\title{
First-Price Equilibrium and Revenue Equivalence in a Sequential Procurement Auction Model
}

Citation for published version (APA):

Reiss, J. P., \& Schoendube, J. R. (2007). First-Price Equilibrium and Revenue Equivalence in a Sequential Procurement Auction Model. Maastricht University School of Business and Economics. METEOR Research Memorandum No. 003 https://doi.org/10.26481/umamet.2007003

Document status and date:

Published: 01/01/2007

DOI:

10.26481/umamet.2007003

Document Version:

Publisher's PDF, also known as Version of record

\section{Please check the document version of this publication:}

- A submitted manuscript is the version of the article upon submission and before peer-review. There can be important differences between the submitted version and the official published version of record.

People interested in the research are advised to contact the author for the final version of the publication, or visit the DOI to the publisher's website.

- The final author version and the galley proof are versions of the publication after peer review.

- The final published version features the final layout of the paper including the volume, issue and page numbers.

Link to publication

\footnotetext{
General rights rights.

- You may freely distribute the URL identifying the publication in the public portal. please follow below link for the End User Agreement:

www.umlib.nl/taverne-license

Take down policy

If you believe that this document breaches copyright please contact us at:

repository@maastrichtuniversity.nl

providing details and we will investigate your claim.
}

Copyright and moral rights for the publications made accessible in the public portal are retained by the authors and/or other copyright owners and it is a condition of accessing publications that users recognise and abide by the legal requirements associated with these

- Users may download and print one copy of any publication from the public portal for the purpose of private study or research.

- You may not further distribute the material or use it for any profit-making activity or commercial gain

If the publication is distributed under the terms of Article $25 \mathrm{fa}$ of the Dutch Copyright Act, indicated by the "Taverne" license above, 
J. Philipp Reiss, Jens Robert Schöndube

First-Price Equilibrium and Revenue Equivalence in a Sequential Procurement Auction Model

$\mathrm{RM} / 07 / 003$

JEL code : C72, D44, L51

\section{METE@R}

Maastricht research school of Economics of TEchnology and ORganizations

Universiteit Maastricht

Faculty of Economics and Business Administration P.O. Box 616

NL - 6200 MD Maastricht

phone : ++31433883830

fax : $\quad++31433884873$ 



\title{
First-Price Equilibrium and Revenue Equivalence in a Sequential Procurement Auction Model*
}

\author{
J. Philipp Reiss \\ Maastricht University, Economics Department \\ PO Box 616, 6200 MD Maastricht, The Netherlands \\ Jens Robert Schöndube \\ University of Magdeburg, Faculty of Economics and Management, \\ PO Box 4120, 39016 Magdeburg, Germany
}

January 2007

\begin{abstract}
We analyze first-price equilibrium bidding behavior of capacity-constrained firms in a sequence of two procurement auctions. In the model, firms with a cost advantage in completing the project auctioned off at the end of the sequence may enter the unfavored first auction hoping to lose it. Equilibrium bidding in both auctions deviates from the standard Symmetric Independent Private Value auction model (SIPV) due to opportunity costs of bidding created by possibly employed capacity.

For this sequential auction model with non-identical objects, we show that revenue equivalence holds.
\end{abstract}

Keywords: sequential first-price auctions, revenue equivalence, endogenous outside options, procurement auction, capacity constraints

JEL classification: C72, D44, L51

*Email addresses: p.reiss@algec.unimaas.nl, jens.schoendube@ww.uni-magdeburg.de. An earlier version of this paper has been circulated under the titel On participation in sequential procurement auctions. We thank Werner Güth and Ulf Schiller for helpful comments and stimulating discussions and gratefully acknowledge comments from Jeannette Brosig, Alfred Luhmer, Barbara Pirchegger, Gerhard Schwödiauer, and audiences at Frankfurt, Fribourg, Heidelberg, Leuven, Maastricht, Magdeburg, Marseille, Mannheim, and Swansea. 


\section{Introduction}

This paper studies first-price equilibrium bidding behavior in a sequential procurement auction model with capacity-constrained firms. Usually procurers differ across regions, firms, and institutions and set independently of each other different auction dates implying a sequence of auctions. Often projects to be auctioned off are similar and offered for execution during the same window of time. Although the sequential nature of procurement auctions is prevalent, most theoretical studies implicitly abstract it away by focussing on a single procurement auction in isolation (e.g. Holt (1980), Riordan and Sappington (1987), McAfee and McMillan (1987b), Dasgupta and Spulber (1989), Rob (1986), Celentani and Ganuza (2002)).

In the few contributions to the sequential procurement auction theory, it is common to assume that any bidding firm has unlimited capacity to execute all sequentially offered projects, see e.g. Luton and McAfee (1986). ${ }^{1}$ However, recent empirical studies on sequential procurement auctions point to the relevance of capacity constraints. De Silva et al. (2002, 2003) find that bids are positively correlated with employed capacity. Jofre-Bonet and Pesendorfer (2000, 2003) report that a firm which did not win a highway procurement contract earlier in a sequence of auctions is twice as likely to enter a subsequent auction than a firm which already won a (large) contract. This evidence suggests that firms are aware of their opportunity costs of bidding created by employed capacity and might be choosy if facing an auction sequence of non-identical procurement contracts.

De Silva et al. (2003) provide an asymmetric, static bidding model to explore differences in bidding patterns observed in road construction auctions. In their model, firms' distributions of completion costs differ from one another which is motivated by the idea that firms are either incumbents or entrants implying that bidders with identical completion costs differ in bidding behavior; particularly, entrants bid more aggressively than incumbents which is statistically confirmed in their empirical analysis. In our paper, we provide an alternative explanation for differing bidding functions in a symmetric, sequential auction model stemming from differences in the option value that firms assign to subsequently auctioned procurement contracts. In this spirit, our model may be viewed as a way to endogenize asymmetries and differences in bidding functions in static models through heterogenous opportunity costs.

We consider a sequence of procurement auctions in the first-price sealed-bid design where projects are stochastically equivalent and bidding firms are capacity-constrained. Since a potential bidding firm finds itself restricted to execution of a subset of sequentially offered heterogenous projects, it must decide which procurement auctions to enter entailing a selection of projects it

\footnotetext{
${ }^{1}$ Exceptions include Elmaghraby (2003) and Gale et al. (2000) where in the latter the cost function can be chosen to effectively allow for capacity constraints.
} 
wishes to possibly end up with. Our model is closely related to that of Gale and Hausch (1994) that, however, utilizes second-price auctions which are rather uncommon in procurement.

For a procurement sequence of identical projects, the analysis of Weber (1983) suggests that equilibrium expected payments of winning bidders coincide and, hence, any firm may want to begin bidding at the start of the sequence. If, however, firms prefer to execute one project to another due to different project completion costs, it is a priori not clear if a firm with more favorable completion costs for projects to be auctioned later in the sequence submit bids for projects auctioned earlier.

This paper studies this kind of entry decision and analyzes how firms refine their bidding strategies with opportunity costs of early bid submission. Our main findings are that the entry decision depends on relative project completion cost levels and equilibrium bidding in both auction stages deviates from the standard Symmetric Independent Private Value auction model (SIPV) and its sequential formulation with homogenous goods and single-unit demand. Firms with lower completion costs for the first project auctioned off always submit bids while firms with lower completion costs for the project subsequently auctioned off only participate if their opportunity costs are not too large. Each firm entering the first auction includes its option value of the second project in its bid for the first project. Moreover, we derive revenue and payoff equivalence for the sequential model with non-identical project contracts.

An experimental investigation of our sequential first-price auction model, see Brosig and Reiss (2007), finds that the bidding deviations from the standard SIPV model predicted by our model are, indeed, observed in the laboratory. This finding emphasizes that opportunity costs of early bid submissions are understood by bidders and form a crucial determinant of bidding behavior.

The next section introduces our model and its symmetric equilibrium. In section 3 , we derive payoff and revenue equivalence. Section 4 investigates differences between the static SIPV model and the sequential model. In particular, we illustrate how the option value of subsequent contract opportunities affects bidding decisions of firms. Section 5 concludes. 


\section{The Model}

There are two risk-neutral firms, each endowed with capacity to complete a single project. ${ }^{2}$ Two projects, $L$ and $M$, are sequentially auctioned off. Subcontracting is prohibitively costly. ${ }^{3}$ The firms' cost of completing any of the two projects are their private information and known to them at the beginning of the dynamic auction game. In order to formalize the similarity of both projects and the aspect that the ranking of completion costs is unknown ${ }^{4}$ to competitors, we assume in the spirit of Gale and Hausch (1994) that projects are stochastically equivalent. In particular, it is common knowledge that firm $i$ 's costs of completion are jointly drawn from $f\left(l_{i}, m_{i}\right)$ with domain $[\underline{c}, \bar{c}]^{2}$ and stochastically equivalent in the sense of $f(l, m)=f(m, l)$ for every $(l, m) \in[\underline{c}, \bar{c}]^{2}$ implying $E\left[L_{i}\right]=E\left[M_{i}\right]$ where $l_{i}$ and $m_{i}$ denote the cost realization of firm $i$ for projects $L$ and $M$ respectively. Although completion costs of a single firm may be correlated across projects, pairs of completion costs of different firms are independently distributed. If cost realizations of firm $i$ are such that $l_{i}<m_{i}$, this firm is said to have a cost advantage for project $L$, the reversed inequality indicates a cost advantage for project $M$.

In each procurement auction, a participating firm may submit a sealed bid where the lowest bid wins the project and the bidded amount is paid in exchange for completion of the project. ${ }^{5}$ However, bids cannot exceed maximum completion costs $\bar{c}$ which may be interpreted as the procurers outside option. We assume that the auctioneer cannot set a price below maximum completion costs $\bar{c}$ and that resale of projects is not feasible. If there happens to be a bidding tie, auctioneers employ a fair chance mechanism to break it. The sequence of auctions begins with the procurement auction of project $L$ where the winner if any is publicly announced before project $M$ is auctioned off. Thus, with two firms, any firm knows if it faces competition in auction $M$ before it submits its bid.

Since both firms are ex ante symmetric, we restrict attention to the case of symmetric

\footnotetext{
${ }^{2}$ Although the restriction that firms are required to complete at most a single project seems severe, closer observation reveals that this element is common in procurement auctions. Firstly, procurers may stipulate exclusive project completion to avoid that its competitors running a similar project gain benefits through a contractor working for both procurers. Secondly, a firm may face capacity constraints if projects run simultaneously and require relatively large amounts of its resources. Finally, firms may voluntarily decide not to execute simultaneously several risky projects to prevent changes in the risk distribution of their entrepreneurial activities.

${ }^{3}$ Empirical studies on procurement bidding (e.g. Jofre-Bonet and Pesendorfer 2000, 2003) find that the probability that a firm participates in an auction and that a participating firm wins the auction decreases in its backlog. This points to the fact that firms regard subcontracting as costly and not always as a feasible option to weaken their capacity constraints.

${ }^{4}$ Unlike the second-price procurement auction model in Elmaghraby (2003) where it is assumed that the second project is always more costly than the first one.

${ }^{5}$ Although the analysis of the second-price auction design is less demanding, we employ the first-price design since otherwise our model's bidding predictions cannot explain real-life data.
} 
perfect Bayesian equilibria. We refer to the representative firm as firm 1 . The strategy of the representative firm is given by $\left(b_{1}^{L}, b_{1}^{M}\right)$ where the bid for auction $L$ is given by $b_{1}^{L} \in \mathbb{R} \cup\{$ no entry $\}$ and $b_{1}^{M} \in \mathbb{R}$ is the firm's bid in auction $M$. In addition to equilibrium bidding functions for each auction stage, a firm's strategy also includes a decision to submit a bid in the first auction or skip bidding for project $L$. Intuitively, there must be a region of cost types where firms reject to bid in auction $L$ since a firm with completion cost $l=\bar{c}$ cannot make any profit by completing this project and, moreover, is - if it has won project $L$ - excluded from participating in auction $M$ where its expected profits may be positive due to more favorable costs of completion $m<\bar{c}$. Obviously, these extreme cost pairs highlight that opportunity costs, which coincide with expected profits from skipping auction $L$, exceed expected profits from bidding for project $L$. In general, firm 1 participates in auction $L$ if its expected profit from bidding exceeds opportunity costs arising from possibly being excluded from bidding for project $M$, formally

$$
E\left[\Pi_{1}^{L+M} \mid\left(l_{1}, m_{1}\right)\right] \geq E\left[\Pi_{1}^{M} \mid m_{1}\right]
$$

where $E\left[\Pi_{1}^{L+M} \mid\left(l_{1}, m_{1}\right)\right]$ denotes firm 1's expected profit if it bids in the procurement auction for project $L$ and - if unsuccessful - continues bidding in auction $M$ and $E\left[\Pi_{1}^{M} \mid m_{1}\right]$ is its expected profit if it skips the first auction and bids only for the subsequently auctioned project $M$. Profits are random since completion costs of any competitor are unknown and determine its bidding behavior.

The firm's decision to skip auction $L$ depends on the relationship of its completion costs. In order to formalize the entry decision we introduce the entry indifference curve $g_{1}:[\underline{c}, \bar{c}] \rightarrow$ $[\underline{c}, \bar{c}]$ that assigns a level for the completion cost of project $L$ to each cost level of project $M$ such that the firm is indifferent between taking part in auction $L$ and skipping it. The entry indifference curve $l_{1}^{\text {crit }}=g_{1}\left(m_{1}\right)$ is implicitly defined by the equality of expected profits from entering auction $L$ and corresponding opportunity cost:

$$
E\left[\Pi_{1}^{L+M} \mid\left(l_{1}^{c r i t}, m_{1}\right)\right]=E\left[\Pi_{1}^{M} \mid m_{1}\right] .
$$

In subsection 2.2, we show that the entry indifference curve defined here exists. Figure 2, p. 12 , illustrates the qualitative properties of the entry indifference curve in equilibrium. Since it cannot be worthwhile for a firm to participate in auction $L$ with $l_{1}>l_{1}^{c r i t}$ but it must be if $l_{1}<l_{1}^{\text {crit }}$, the firm's decision rule to participate in auction $L$ is given by

$$
\varepsilon_{1}\left(l_{1}, m_{1}\right)= \begin{cases}\text { Enter Auction } L & \text { if } l_{1} \leq g_{1}\left(m_{1}\right) \\ \text { Skip Auction } L & \text { if } l_{1}>g_{1}\left(m_{1}\right)\end{cases}
$$

Next we derive the equilibrium bidding functions for both procurement auctions since these determine expected profits on which the entry indifference curve $g_{1}\left(m_{1}\right)$ depends. Since the 
equilibrium bidding functions depend on the equilibrium entry indifference curve themselves, we derive these for any entry indifference curve $g_{1}\left(m_{1}\right)$. The equilibrium indifference curve is denoted by $g(m)$ and is identified given equilibrium bidding behavior. Thus equilibrium bidding and the entry indifference curve are simultaneously determined.

\subsection{Equilibrium Bidding Functions}

Both auctions employ the first-price sealed-bid auction format where the lowest bid wins. ${ }^{6}$ Under this auction design, the symmetric equilibrium strategy in a one-shot procurement auction is well-known, e.g. Holt (1980) and Cohen and Loeb (1990), and summarized in lemma 1.

Lemma 1 Cohen and Loeb (1990), Equilibrium bidding in a first-price sealed-bid procurement auction

Let project completion costs of two risk-neutral firms that bid for a single project contract be private information and independently and identically distributed according to $c d f H(c), c \in[\underline{c}, \bar{c}]$. Then, the symmetric equilibrium bidding function is $b(c)=c+\int_{c}^{\bar{c}}[1-H(x)] d x /[1-H(c)]$. (for a proof see the referees' appendix)

For our sequential procurement auction game, we derive the equilibrium bidding function for each of the two project auctions by application of this lemma to our specific context with additional strategic interaction: In the first auction stage every firm knows that a second auction follows. In the second auction stage, each bidder receives information on the outcome of the first auction $L$.

Consider first the auction for project $L$. Any of the two firms that enters the first auction anticipates that in case it does not win the first auction, it will be the only bidder in the subsequent auction $M$ where it will receive $\bar{c}-m$. Thus, it might submit a relatively high bid for project $L$, since it is, at least partially, insured against losing the first auction. In particular, a firm with a cost advantage ${ }^{7}$ for project $M$ knows that the largest payoff it can receive is $\bar{c}-m$ from being the only bidder for project $M$ since its largest payoff in auction $L$ is $\bar{c}-l$ which must be smaller due to the firm's cost advantage. Thus, provided the firm decides to participate in auction $L$, it seeks to lose the first auction and minimizes its chances of winning project $L$ by submitting the highest feasible bid which simultaneously maximizes its payoff from accidentally winning it. In contrast, if a firm has a cost advantage for project $L$, then it tops its completion cost $l$ with its certain return from auction $M$ and uses this revised cost parameter $\lambda \equiv l+\bar{c}-m$

\footnotetext{
${ }^{6}$ Cf. Vickrey (1961), McAfee and McMillan (1987a) or Milgrom (1989) for a description of the first-price sealed-bid auction design.

${ }^{7}$ Recall that the term cost advantage refers to a comparison across projects rather than a comparison across firms.
} 


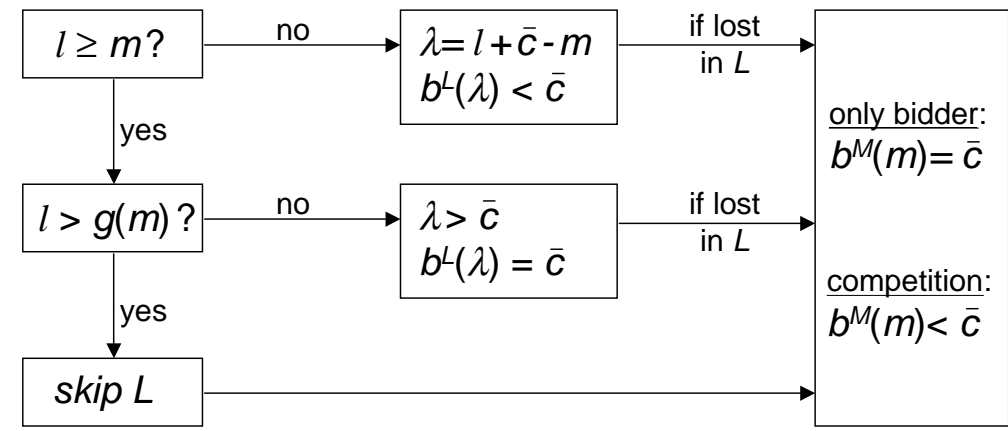

Figure 1: Equilibrium structure of the sequential procurement auction game

in auction $L$. Intuitively it uses its total cost of executing project $L$ that include the direct project $\operatorname{cost} l$ and the opportunity cost of winning project $L, \bar{c}-m$ (=benefit of not-winning auction $L$ ): Any firm taking part in auction $L$ treats $\bar{c}-m$ as a safe profit. In case it wins project $L$, it pays the cost of executing this project and 'repays' the amount $\bar{c}-m$.

If there is no bidding competition in the auction for project $M$, then any firm bidding for it submits the maximum feasible bid to maximize profits. If it is not the only bidder then it receives the additional information that its competitor did not enter auction $L$, too. In response it updates its belief about its competitor's cost parameter for project $M$ since skipping auction $L$ might not be equilibrium behavior for every type. The appropriate a posteriori pdf is denoted by $f_{M \mid S k i p}(m)$ and gives the (equilibrium) density that a firm with completion cost realization $m$ for project $M$ bids only in auction $M$. Put differently, $f_{M \mid \text { Skip }}(m)$ is the marginal pdf of $f(l, m)$ conditional on the fact that completion cost pair $(l, m)$ leads the firm to skip auction $L$.

Figure 1 illustrates the equilibrium structure of the game.

\section{Proposition 2 Equilibrium bidding functions in auctions $L$ and $M$}

The equilibrium bidding functions of a firm with completion cost pair $(l, m) \in[\underline{c}, \bar{c}]^{2}$ are given by:

$$
\text { (a) } b^{L}(\lambda)= \begin{cases}\bar{c} & \text { if } l \geq m \\ \lambda+\int_{\lambda}^{\bar{c}}\left[1-F_{\lambda}(x)\right] d x /\left[1-F_{\lambda}(\lambda)\right] & \text { otherwise }\end{cases}
$$

if it submits a bid for project $L$ where $\lambda \equiv l+\bar{c}-m$ and $F_{\lambda}(x)=\int_{\underline{c}}^{x} \int_{\bar{c}+\underline{c}-\lambda}^{\bar{c}} f(m-\bar{c}+\lambda, m) d m d \lambda$ with $x \in[\underline{c}, \bar{c}]$.

(b) $b^{M}(m)= \begin{cases}\bar{c} & \text { if it is the only bidder } \\ m+\int_{m}^{\bar{c}}\left[1-F_{M \mid \text { Skip }}(x)\right] d x /\left[1-F_{M \mid \text { Skip }}(m)\right] & \text { otherwise }\end{cases}$

if it submits a bid for project $M$ where $f_{M \mid S k i p}(x)=\left[\int_{g(x)}^{\bar{c}} f(l, x) d l\right] /\left[\int_{\underline{c}}^{\bar{c}} \int_{g(t)}^{\bar{c}} f(l, t) d l d t\right]$ and $F_{M \mid \text { Skip }}(x)=\int_{\underline{c}}^{x} f_{M \mid \text { Skip }}(s) d s$ and $g(x)$ denotes the competitor's entry indifference curve. 


\section{Proof}

Consider first part (b): Before bidding for auction $M$, any firm knows if its competitor won auction $L$. If the competitor entered auction $L$, the firm remains the only bidder in auction $M$ and maximizes its return by submitting the largest feasible bid equaling $\bar{c}$. If, however, its competitor skipped auction $L$, the firm infers that its competitor's completion cost pair must satisfy $L>g(M)$ (to be determined later) and Bayesian updating of the firm's cost belief regarding its competitor leads to the a posteriori pdf $f_{M \mid S k i p}(x)$. Appealing to lemma 1 leads to $b^{M}(m)$.

For (a), note that a firm receives $\bar{c}-m$ in auction $M$ if it loses auction $L$. If its completion costs satisfy $m \leq l$ then it cannot receive a larger return in auction $L, \bar{c}-m \geq \bar{c}-l$ by assumption. Thus the firm chooses to receive the largest feasible return from auction $L$ by bidding $\bar{c}$ which also maximizes the frequency it ends up with the larger return from auction $M$, provided it submits a bid for project $L$.

In case the firm has a cost advantage for project $L$, i.e. $l<m$, its expected profit from participating in auction $L$ with any bid $b_{1}^{L} \in[\underline{c}, \bar{c}]$ and possibly in auction $M$ is given by $E\left[\Pi_{1}^{L+M} \mid l_{1}<m_{1}\right]=\left(b_{1}^{L}-l_{1}\right) \cdot \operatorname{Pr}\left(b_{1}^{L}\right.$ wins auction $\left.L\right)+\left(\bar{c}-m_{1}\right) \cdot\left[1-\operatorname{Pr}\left(b_{1}^{L}\right.\right.$ wins auction $\left.\left.L\right)\right]$.

Using firm 1's total cost parameter $\lambda_{1} \equiv l_{1}+\bar{c}-m_{1}$, this can be rewritten as

$$
E\left[\Pi_{1}^{L+M} \mid l_{1}<m_{1}\right]=\left(b_{1}^{L}-\lambda_{1}\right) \cdot \operatorname{Pr}\left(b_{1}^{L} \text { wins auction } L\right)+\bar{c}-m_{1}
$$

From firm 1's perspective $\bar{c}-m_{1}$ is a known constant and its expected profit from bidding in auction $L, E\left[\Pi_{1}^{L+M} \mid l_{1}<m_{1}\right]$, is maximized if $b_{1}^{L}$ maximizes

$$
Z\left(\lambda_{1}\right):=\left(b_{1}^{L}-\lambda_{1}\right) \cdot \operatorname{Pr}\left(b_{1}^{L} \text { wins auction } L\right)
$$

where $l_{1}<m_{1} \Leftrightarrow \lambda_{1}<\bar{c}$ by definition. Suppose there exists a symmetric equilibrium bidding function $b^{L}(\lambda)$ that maximizes $Z$ such that it is strictly increasing for $\lambda<\bar{c}, b^{L}(\lambda)<\bar{c}$ for $\lambda<\bar{c}$, and $b^{L}(\lambda)=\bar{c}$ for $\lambda \geq \bar{c}$. Since $b^{L}(\lambda)$ is strictly increasing on $[\underline{c}, \bar{c}]$, there exists an inverse on that domain denoted by $b^{-1, L}\left(b^{L}\right)$. Given that firm 1's competitor adheres to this equilibrium bidding function, firm 1 (with a cost advantage for project $L$ ) wins always the first round if its competitor has a cost advantage for project $M, \lambda_{2} \geq \bar{c}$. It wins project $L$ too, if it bids an amount that corresponds to a lower total cost type $\lambda_{1}=b^{-1, L}\left(b^{L}\right)$ than the one of its competitor $\lambda_{2}$. Denoting the cdf of total cost types by $F_{\lambda}(\lambda),(2)$ can be rewritten $\operatorname{as}^{8}$

$$
Z\left(\lambda_{1}\right)=\left(b_{1}^{L}-\lambda_{1}\right) \cdot\left[1-F_{\lambda}\left(b^{-1, L}\left(b_{1}^{L}\right)\right)\right]
$$

\footnotetext{
${ }^{8}$ Here the fact is used that types with a cost advantage for project $L$ always enter the first auction. This is formally confirmed in lemma 4.
} 
where $f_{\lambda}(\lambda)=\int_{\bar{c}+\underline{c}-\lambda}^{\bar{c}} f(m-\bar{c}+\lambda, m) d m$ and $F_{\lambda}(\bar{c})=1 / 2$. If $b_{1}^{* L}$ maximizes $Z$ then $\partial Z^{*} / \partial b_{1}^{L}=0$ and differentiation of $(3)$ at the optimum w.r.t. $\lambda_{1}$ yields

$$
\frac{d Z^{*}}{d \lambda_{1}}=-\left[1-F_{\lambda}\left(b^{-1, L}\left(b_{1}^{* L}\right)\right] .\right.
$$

Integration in the boundaries $\left[\lambda_{1}, \bar{c}\right]$ together with the fact that in a Nash equilibrium $b_{1}^{* L}$ must coincide with the value of the equilibrium bidding function at the true cost type $\lambda_{1}$ leads to

$$
Z^{*}(\bar{c})-Z^{*}\left(\lambda_{1}\right)=-\int_{\lambda_{1}}^{\bar{c}}\left[1-F_{\lambda}(x)\right] d x .
$$

Since $b^{L}(\bar{c})=\bar{c}$, we have $Z^{*}(\bar{c})=0$ and obtain with (3) at its optimum the equilibrium bidding function for $\lambda_{1}<\bar{c}$ :

$$
b^{L}\left(\lambda_{1}\right)=\lambda_{1}+\frac{\int_{\lambda_{1}}^{\bar{c}}\left[1-F_{\lambda}(x)\right] d x}{1-F_{\lambda}\left(\lambda_{1}\right)}
$$

\subsection{Entry Decision}

In this section, we derive the entry indifference curve (1) under the assumption of equilibrium bidding that is summarized in proposition 2. Obviously the expected profit from bidding in auction $L$ and possibly in auction $M, E\left[\Pi_{1}^{L+M} \mid\left(l_{1}, m_{1}\right)\right]$, always exceeds the expected profit from skipping auction $L, E\left[\Pi_{1}^{M} \mid m_{1}\right]$ if firm 1 has a cost advantage for project $L$ (i.e. $l_{1} \leq m_{1}$ ): the expected profit from entering auction $L$ and possibly $M$ is at least as large as $\bar{c}-m_{1}$. To see this suppose that the firm would bid $\bar{c}$ in auction $L$. Then it receives in expectation $\left(\bar{c}-l_{1}\right) \cdot \operatorname{Pr}($ won $L)+\left(\bar{c}-m_{1}\right) \cdot \operatorname{Pr}($ lost $L) \geq \bar{c}-m_{1}$. For any bid in auction $M$, the expected profit from skipping $L, E\left[\Pi_{1}^{M} \mid m_{1}\right]$, must be lower than $\bar{c}-m_{1}$ since there is a positive probability of bidding competition in auction $M$. It follows that (1) can only hold if $l_{1}^{\text {crit }}>m_{1}$ and that without loss of generality the entry indifference curve is defined by:

$$
E\left[\Pi_{1}^{L+M} \mid\left(l_{1}^{\text {crit }}>m_{1}, m_{1}\right)\right]=E\left[\Pi_{1}^{M} \mid m_{1}\right] .
$$

In order to explicitly state equation (4), consider first its left-hand side. A firm with a cost advantage for project $M$ that enters auction $L$ bids $\bar{c}$ in auction $L$ and if it loses $\bar{c}$ in auction $M$. This strategy results in four events summarized in the next table where the probabilities depend on firm 1's belief that firm 2 acts in accordance with the entry indifference curve $g_{2}\left(M_{2}\right)$.

\begin{tabular}{|ll|c|c|}
\hline \multicolumn{2}{|c|}{ Events if firm 1 bids $\bar{c}$ in auction $L$} & Payoff & Probability \\
\hline A $\quad$ it is the only bidder & $\bar{c}-l_{1}$ & $\operatorname{Pr}\left(L_{2}>g_{2}\left(M_{2}\right)\right)$ \\
B $\quad$ the competitor bids $\bar{c}$ and firm 1 wins $L$ & $\bar{c}-l_{1}$ & $\operatorname{Pr}\left(g_{2}\left(M_{2} \geq L_{2} \geq M_{2}\right) \cdot 0.5\right.$ \\
C $\quad$ the competitor bids $\bar{c}$ and firm 1 loses $L$ & $\bar{c}-m_{1}$ & $\operatorname{Pr}\left(g_{2}\left(M_{2}\right) \geq L_{2} \geq M_{2}\right) \cdot 0.5$ \\
D & the competitor bids less than $\bar{c}$ & $\bar{c}-m_{1}$ & $\operatorname{Pr}\left(L_{2}<M_{2}\right)$ \\
\hline
\end{tabular}


Hence the expected benefit to a firm with a cost advantage for project $M$ from starting bidding for project $L$ with $b^{L}=\bar{c}$ and then continuing bidding in auction $M$ after losing auction $L$ is given by

$$
\begin{aligned}
E\left[\Pi_{1}^{L+M} \mid\left(l_{1}>m_{1}, m_{1}\right)\right]= & \int_{\underline{c}}^{\bar{c}} \int_{g_{2}\left(m_{2}\right)}^{\bar{c}} f\left(l_{2}, m_{2}\right) d l_{2} d m_{2} \cdot\left(\bar{c}-l_{1}\right) \\
& +\int_{\underline{c}}^{\bar{c}} \int_{m_{2}}^{g_{2}\left(m_{2}\right)} \frac{f\left(l_{2}, m_{2}\right)}{2} d l_{2} d m_{2} \cdot\left[2 \bar{c}-\left(l_{1}+m_{1}\right)\right] \\
& +\int_{\underline{c}}^{\bar{c}} \int_{\underline{c}}^{m_{2}} f\left(l_{2}, m_{2}\right) d l_{2} d m_{2} \cdot\left(\bar{c}-m_{1}\right)
\end{aligned}
$$

Now, consider the right-hand side of (4). If firm 1 skips auction $L$ there are three events depending on the entry behavior of its competitor. Again firm 1 assesses the probabilities of these events given its belief about the competitor's entry indifference curve $g\left(M_{2}\right)$.

\begin{tabular}{|ll|c|c|}
\hline & Events if firm 1 skips auction $L$ & Payoff & Probability \\
\hline E & no bidding competition & $\bar{c}-m_{1}$ & $\operatorname{Pr}\left(L_{2} \leq g_{2}\left(M_{2}\right)\right)$ \\
F & firm 1 wins project $M$ & $b^{M}\left(m_{1}\right)-m_{1}$ & $\operatorname{Pr}\left(M_{2}>m_{1} \wedge L_{2}>g_{2}\left(M_{2}\right)\right)$ \\
G & the competitor wins project $M$ & 0 & $\operatorname{Pr}\left(M_{2}<m_{1} \wedge L_{2}>g_{2}\left(M_{2}\right)\right)$ \\
\hline
\end{tabular}

Thus the expected benefit to firm 1 with a cost advantage for project $M$ from skipping bidding for project $L$ can be written as:

$$
\begin{aligned}
E\left[\Pi_{1}^{M} \mid m_{1}\right] & =\left(\bar{c}-m_{1}\right) \int_{\underline{c}}^{\bar{c}} \int_{\underline{c}}^{g_{2}\left(m_{2}\right)} f\left(l_{2}, m_{2}\right) d l_{2} d m_{2} \\
& +\int_{m_{1}}^{\bar{c}} \int_{g_{2}\left(m_{2}\right)}^{\bar{c}}\left[b^{M}\left(m_{1}\right)-m_{1}\right] \cdot f\left(l_{2}, m_{2}\right) d l_{2} d m_{2}
\end{aligned}
$$

A standard result in auction theory is that in first-price sealed-bid auctions bids are formed such that they equal the expected second-order statistic from the relevant type pool (conditional on the own type being the first-order statistic). Thus, $b^{M}\left(m_{1}\right)$ in the last term in $E\left[\Pi_{1}^{M} \mid m_{1}\right]$ can be substituted by $m_{2}$. This is formally confirmed by lemma 3 implying:

$$
\begin{aligned}
E\left[\Pi_{1}^{M} \mid m_{1}\right] & =\left(\bar{c}-m_{1}\right) \int_{\underline{c}}^{\bar{c}} \int_{\underline{c}}^{g_{2}\left(m_{2}\right)} f\left(l_{2}, m_{2}\right) d l_{2} d m_{2} \\
& +\int_{m_{1}}^{\bar{c}} \int_{g_{2}\left(m_{2}\right)}^{\bar{c}}\left(m_{2}-m_{1}\right) \cdot f\left(l_{2}, m_{2}\right) d l_{2} d m_{2}
\end{aligned}
$$

Clearly $E\left[\Pi_{1}^{M} \mid m_{1}\right]$ decreases in $m_{1}$ and is independent of $l_{1}$. 
Lemma 3 Firm 1's expected profit from equilibrium bidding in auction $M$ if there is bidding competition and $b_{1}^{M}=b^{M}\left(m_{1}\right)$ is equal to the expected profit from bidding the expected secondorder statistic of completion costs given that firm 1's completion costs are the lowest, i.e.

$$
\int_{m_{1}}^{\bar{c}} \int_{g_{2}\left(m_{2}\right)}^{\bar{c}}\left(b_{1}^{M}-m_{1}\right) \cdot f\left(l_{2}, m_{2}\right) d l_{2} d m_{2}=\int_{m_{1}}^{\bar{c}} \int_{g_{2}\left(m_{2}\right)}^{\bar{c}}\left(m_{2}-m_{1}\right) \cdot f\left(l_{2}, m_{2}\right) d l_{2} d m_{2} .
$$

Proof See the appendix.

Lemma 4 Boundaries of the entry indifference curve $g(m)$

Let $l_{1}^{\text {crit }}=g_{1}\left(m_{1}\right)$ be implicitly defined by $E\left[\Pi_{1}^{L+M} \mid\left(l_{1}^{\text {crit }}, m_{1}\right)\right]=E\left[\Pi_{1}^{M} \mid m_{1}\right]$. If $g_{1}\left(m_{1}\right)$ exists, then $m_{1}<g_{1}\left(m_{1}\right)<\bar{c}$ for $m_{1} \in[\underline{c}, \bar{c})$ and $g_{1}(\bar{c})=\bar{c}$.

Proof See the appendix.

The existence of the entry indifference curve in symmetric equilibrium is verified in proposition 5 where also its properties are given. Its proof contains a differential equation whose solution is the symmetric equilibrium indifference curve $g(m)$. Figure 2 illustrates these results for a representative firm with completion cost pair $(l, m)$.

Proposition 5 For the symmetric perfect Bayesian equilibrium characterized by the representative firm's strategy $\left[b^{L}(l, m), b^{M}(m), \varepsilon(m)\right]$ and the density function $f(l, m)$ :

(a) There exists a (nonempty) compact and convex set of completion cost pairs where a firm bids for project $L$ although it has a cost advantage for completing project $M$. This subset is defined by $G=\left\{(l, m) \in[\underline{c}, \bar{c}]^{2} \mid m \leq l \leq g(m)\right\}$.

(b) The critical value function $g(m)$ exists and

(i) $m<g(m)<\bar{c}$ if $m \in[\underline{c}, \bar{c}), g(\bar{c})=\bar{c}, g(\underline{c})>\underline{c}$,

(ii) $g^{\prime}(m)>0$,

(iii) $g^{\prime \prime}(m)<0$ if $m \in[\underline{c}, \bar{c})$ and $g^{\prime \prime}(\bar{c})=0$.

Proof See the appendix.

Consideration of proposition 5 leads to the conclusion that any firm always enters auction $L$ if it faces a cost advantage for this project, i.e. $l \leq m$. Then it earns at least $\bar{c}-m$ while skipping auction $L$ leaves it with running the risk of lower profits in case its competitor also skipped the first auction resulting in lower expected profits of this strategy. In contrast, a cost advantage 


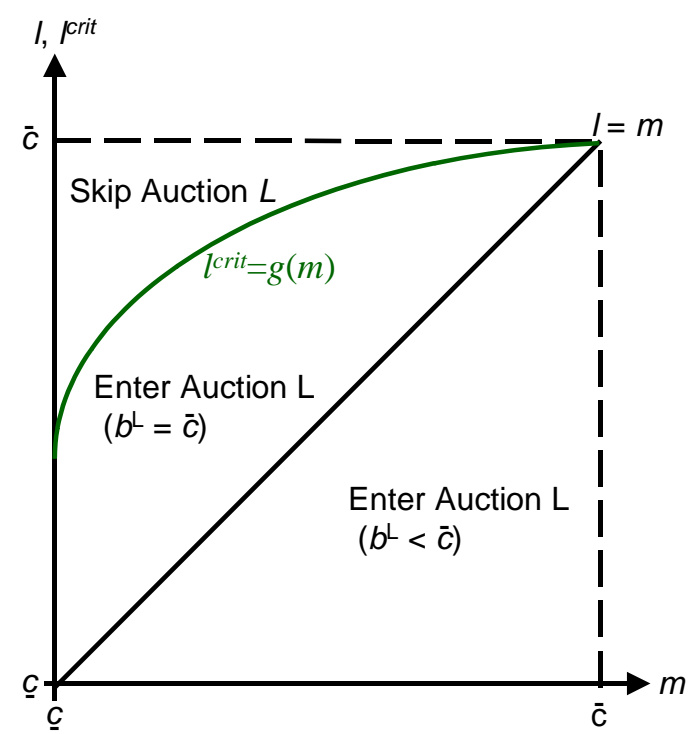

Figure 2: Equilibrium entry behavior

for completing project $M$ implies the impossibility of the firm to secure itself the same return in auction $L$ as it could earn in auction $M$ being the only bidder. However, if the competing firm has a strong cost advantage for project $M$ and skipped auction $L$, then there is competition in the second auction with the risk of low or even zero profits due to aggressive bidding. Therefore a firm may wish to participate in the first auction and win the unloved project $L$ at a high price to insure itself against low profits resulting from fierce competition in the second auction, although it actually prefers losing the auction for project $L$.

Although our sequential auction model is highly stylized in the sense that we assume just two bidders implying that there is the possibility of being the sole bidder in the second auction, we conjecture that our results seem to apply also for a more general number of bidders. The reason why there appears an endogenous option value in the first auction, influencing equilibrium bidding for auction $L$ and equilibrium non-entry, is that a non-winning bidder in the first auction anticipates a certain profit in the second auction when it will be the only bidder. If there are more than two bidders in the model, there is always competition in the second auction. However, there remains an option value generated by the opportunity to bid in the second auction which, in this case, is not a fixed payment but rather an uncertain payment that is fixed in expectation. Given such an option value, there are bidders, e.g. those faced with maximum cost if completing the first project, that prefer to skip the first auction and only bid in the second one. It follows that our results do not hinge on the number of bidders. 


\section{$3 \quad$ Payoff and Revenue Equivalence}

In this section we state a revenue equivalence result for our sequential auction model with nonidentical bidder costs across projects. For a sequential auction of identical objects with bidders that demand a single object, revenue equvialence holds (Weber, 1983; Maskin and Riley, 1989). For our auction model it is a priori unclear if a similiar revenue equivalence result continues to apply since in our model bidders' cost types for various projects are non-identical.

For a sequence of two completely unrelated standard auctions, i.e. two subsequent one-shot auctions, it is obvious that revenue equvialence holds in each of the "stage" auctions (Myerson, 1981; Riley and Samuelson, 1981). In our sequence of auctions, the number of bidders in the first stage auction is not fixed and the number of buyers in the second stage auction is unknown ex ante ${ }^{9}$, so that our result extends standard revenue equivalence.

Following Riley and Samuelson (1981), we impose the following five properties on auction designs adapted to our context that guarantee revenue equivalence for a class of auctions. Property A5 is motivated by our procurement context where we require the buyer to compensate any types' cost but not more and not less.

A1 The project buyer accepts a bid of every firm unless it exceeds the largest feasible bid.

A2 The project is awarded to a firm that submits the lowest bid.

A3 The auction design does only discriminate between bidders on the basis of submitted bids.

A4 There exists a symmetric Bayesian equilibrium with an increasing bidding function.

A5 The auction design pays only amounts in the interval $[\underline{c}, \bar{c}]$ to a bidding firm. Furthermore, it guarantees that the highest cost-type receives a compensation equal to its cost $\bar{c}$.

Definition 6 Auction class $\Gamma$ comprises all auction designs satisfying properties $A 1-A 5$.

Lemma 7 Expected profit if skipping auction $L$.

(a) No competition in $M$ : Suppose that there is a single bidder in the second auction $M$. Then, the bidder's expected profit is given by $\pi_{1}^{M \mid N C}\left(m_{1}\right)=\bar{c}-m_{1}$.

(b) Competition in M: Suppose that there are two bidders in the second auction M. Then, bidder 1's expected profit is given by $\pi_{1}^{M \mid C}\left(m_{1} \mid g_{2}().\right)=\int_{m_{1}}^{\bar{c}}\left[1-F_{M \mid \text { Skip }}(s)\right] d s$ where the distribution is defined as in proposition 2.

\footnotetext{
${ }^{9}$ In the first stage auction the number of bidders is 0,1 or 2 ; in the second stage auction it is either 1 or 2.
} 
(c) Ex ante profit from skipping auction L: Suppose that a bidder considers skipping the first auction L. Then, his expected profit is given by $E\left[\Pi^{M} \mid m_{1} ; g_{2}().\right]=p^{s k i p \mid g_{2}(.)} \cdot \pi_{1}^{M \mid C}\left(m_{1}\right)+$ $\left[1-p^{\text {skip } \mid g_{2}(.)}\right] \cdot \pi_{1}^{M \mid N C}\left(m_{1} \mid g_{2}().\right)$ where $p^{\text {skip } \mid g_{2}(.)}$ denotes the probability that the competitor skips the first auction implying competition in the second auction conditional on entry behavior of the competitor, i.e. $p^{\text {skip } \mid g_{2}(.)}=\int_{\underline{c}}^{\bar{c}} \int_{g_{2}(m)}^{\bar{c}} f(l, m) d l d m$.

\section{Proof}

(a) By A5, the largest buyer payment to a firm is $\bar{c}$ since the auction design guarantees that the project cost of the highest cost-type is fully covered. If there is no competition, the only bidder bids such that it pretends to have to incur maximum cost $\bar{c}$ which it precisely receives.

(b) In auction $M$ with competition, there are two bidders that have observed that the competitor did not enter auction $L$. Each bidder updates the distribution about competitor's cost for completing project $M$ resulting in $F_{M \mid S k i p}$. Since this is a standard one-shot auction in the last stage of the sequential auction game, the result immediately follows. [See the referee's appendix, page 7.3.]

(c) The given expression is the definition of the expected firm's profit if skipping auction $L$.

Proposition 8 (Payoff equivalence) If the two auction designs utilized in auctions $L$ and $M$ are in class $\Gamma$, each firm receives the same expected equilibrium profit and there is invariance of equilibrium entry behavior.

\section{Proof}

We have to show that each cost type $\left(l_{1}, m_{1}\right)$ receives the same expected profit in equilibrium. Our strategy of proof is as follows: First, we show that a firm with a cost advantage for the first project, i.e. $l_{1}<m_{1}$, always enters the first auction and receives the same expected profit from its equilibrium strategy "enter $L$ and possibly $M$ (where $l_{1}<m_{1}$ )" independently of the auction designs utilized in $L$ and $M$. Second, we show that for a given entry indifference curve, changes in the auction design do not change expected profits from the strategies "enter $L$ and possibly $M$ (where $l_{1} \geq m_{1}$ )" and "skip $L$ ".

1. If a firm with a cost advantage for the first project, i.e. $l_{1}<m_{1}$, does not enter the first auction, its expected profit cannot exceed $\bar{c}-m_{1}$ due to the fact that $\bar{c}$ is the largest payment that any auction design in class $\Gamma$ allows. However, since $\bar{c}-l_{1}>\bar{c}-m_{1}$, entering the first auction always offers the possibility to earn a higher expected profit if entering the first auction.

Now we derive the expected equilibrium profit if a firm with a cost advantage for project $L$ enters the first auction. Let the specific payment rule according to auction design $L$ to bidder 1 be given by the function $\rho^{L}\left(b_{1}^{L}, b_{2}^{L}\right)$ where $b_{i}^{L}$ specifies the bid of bidder $i$ in auction 
L. Assuming that there exists an equilibrium bidding strategy $b^{L}: \mathbb{R} \rightarrow \mathbb{R} \cup\{$ no entry $\}$ that is strictly increasing on $[\underline{c}, \bar{c}]$ and that firm 2 follows where $\lambda_{2}=l_{2}+\bar{c}-m_{2}$, firm 1's expected payment from imitating type $x_{1}$ in auction $L$ is $R^{L}\left(x_{1}\right)=E\left[\rho^{L}\left(b^{L}\left(x_{1}\right), b^{L}\left(\lambda_{2}\right)\right)\right]$ and the firm's equilibrium profit is:

$$
E\left[\Pi^{L+M} \mid l_{1}<m_{1}\right]=R^{L}\left(x_{1}\right)-\operatorname{Pr}\{\operatorname{win} L\} l_{1}+[1-\operatorname{Pr}\{\operatorname{win} L\}]\left(\bar{c}-m_{1}\right)
$$

which can be rewritten as

$$
E\left[\Pi^{L+M} \mid l_{1}<m_{1}\right]=R^{L}\left(x_{1}\right)-\left[1-F_{\lambda}\left(x_{1}\right)\right] \lambda_{1}+\bar{c}-m_{1}
$$

where $\lambda_{1}=l_{1}+\bar{c}-m_{1}$ and $F_{\lambda}($.$) is defined as in proposition 2. E\left[\Pi^{L+M} \mid l_{1}<m_{1}\right]$ is maximized if $Q=R^{L}\left(x_{1}\right)-\left[1-F_{\lambda}\left(x_{1}\right)\right] \lambda_{1}$ is maximized. $Q$ can be interpreted as the expected profit if opportunity costs are included. Maximizing $Q$ leads to the following FOC for all $\lambda_{1} \in[\underline{c}, \bar{c})$ at the Nash optimum $\lambda_{1}=x_{1}$

$$
\frac{d R^{L}\left(x_{1}\right)}{d x_{1}}=-\frac{d F_{\lambda}\left(x_{1}\right)}{d x_{1}} \lambda_{1}
$$

After substituting the Nash condition $\lambda_{1}=x_{1}$ and integration in the boundaries $\left[\lambda_{1}, \bar{c}\right]$ we obtain

$$
R^{L}\left(\lambda_{1}\right)=R^{L}(\bar{c})+\int_{\lambda_{1}}^{\bar{c}} s d F_{\lambda}(s) .
$$

Note that $R^{L}\left(\lambda_{1}\right)$ is discontinuous at $\lambda_{1}=\bar{c}$ and the left-side limit is $\lim _{\lambda_{1} \rightarrow \bar{c}^{-}}=\frac{\bar{c}}{2} \cdot{ }^{10}$ If $\lambda_{1}=\bar{c}$ the firm bids as if it faces maximum cost for project $L$ and receives payment $\bar{c}$ if it wins the auction. However, it wins the auction only if firm 2 has no cost advantage for project $L$ and skips the auction or if it is favored by a fair coin flip due to a bidding tie. It follows that the probability that the firm wins $\bar{c}$ is strictly less than $1 / 2$ implying the discontinuity of $R^{L}\left(\lambda_{1}\right)$. Since $R^{L}(\bar{c})$ in equation (6) is the upper limit of an integral, we can use its left-side limit to substitute it in (6) which yields after integration by parts of the second term

$$
R^{L}\left(\lambda_{1}\right)=\bar{c}-F_{\lambda}\left(\lambda_{1}\right) \lambda_{1}-\int_{\lambda_{1}}^{\bar{c}} F_{\lambda}(s) d s \quad \text { if } l_{1}<m_{1} \Leftrightarrow \lambda_{1}<\bar{c}
$$

The expression $R^{L}\left(\lambda_{1}\right)$ gives the expected equilibrium payment in auction $L$ to firm 1 faced with a cost advantage for project $L$. Since a firm's cost type is invariant to changes of the auction design, it follows that the expected profit for firms with a cost advantage for project $L$ is independent of the particular auction design if it is in class $\Gamma$.

\footnotetext{
${ }^{10}$ Every type $\lambda \in[\underline{\mathrm{c}}, \bar{\lambda}]$ with $\bar{\lambda}=2 \bar{c}-\underline{\mathrm{c}}$, or equivalently each type with no cost advantage for auction $L$, i.e. $l \geq m$, either skips auction $L$ or bids as if having maximum cost $\bar{c}$ for project $L$. It follows from the increasing bidding function $b^{L}($.$) that every firm with a cost advantage for auction L(\lambda<\bar{c})$ wins the auction if the competitor has no cost advantage for project $L(\lambda \geq \bar{c})$. The probability that the competitor has no cost advantage for project $L$ is $1 / 2$. Since the highest auction payment in auction $L$ to a bidder with maximum cost is $\bar{c}$, the expected payment from bidding in auction $L$ converges to $\bar{c} / 2$ as a firm's type approaches $\bar{c}$.
} 
2. Using the fact that only firms with no cost advantage for project $L$ skip the first auction (see the first part of the given proof), the entry indifference curve is defined by

$$
E\left[\Pi^{L+M} \mid\left(l^{c r i t}>m, m\right)\right]=E\left[\Pi^{M} \mid m\right]
$$

where $l^{\text {crit }}=g(m)$. For the setting where both auctions are in the first-price design, we have already shown that there exists an entry indifference curve, here denoted by $g^{\mathrm{fp}}(m)$, such that $(7)$ holds. Here we show that, given entry indifference curve $g^{\mathrm{fp}}($.$) , any$ combination of auction designs in class $\Gamma$ utilized in auctions $L$ and $M$, leaves the expected payoffs $E\left[\Pi^{L+M} \mid(l>m, m) ; g^{\mathrm{fp}}().\right]$ and $E\left[\Pi^{M} \mid m ; g^{\mathrm{fp}}().\right]$ unaffected, so that (7) continues to hold and $g^{\mathrm{fp}}($.$) is an equilibrium entry indifference curve for any combination of auctions$ designs in $\Gamma$. Lemma 7 demonstrates that $E\left[\Pi^{M} \mid m, g^{\mathrm{fp}}().\right]$ is invariant to arbitrary changes of the auction designs. To see that $E\left[\Pi^{L+M} \mid(l>m, m) ; g_{2}().\right]$ is invariant to arbitrary changes of the auction design, consider its definition:

$$
\begin{aligned}
E\left[\Pi_{1}^{L+M} \mid\left(l_{1}>m_{1}, m_{1}\right) ; g_{2}(.)\right]= & p^{\text {skip } \mid g_{2}(.)} \cdot\left(\bar{c}-l_{1}\right) \\
& +\left[\frac{1}{2}-p^{\text {skip } \mid g_{2}(.)}\right] \cdot \frac{\bar{c}-l_{1}+\bar{c}-m_{1}}{2} \\
& +\frac{1}{2} \cdot\left(\bar{c}-m_{1}\right)
\end{aligned}
$$

The first line A corresponds to the event that the other firm skips the first auction. Since the firm has no cost advantage for the project $L$, it bids in auction $L$ as if it has maximum cost for project $L$ and therefore receives in the event of winning auction $L$ the payment $\bar{c}$. With probability of $\frac{1}{2}$, the competitor has no cost advantage for project $L$. It follows that the probability that the firm has no cost advantage and does not skip auction $L$ is $\frac{1}{2}-p^{\text {skip } \mid g_{2}(.)}$. In this event, line $\mathrm{B}$, there is a bidding tie in auction $L$ that is fairly resolved. The third line, $\mathrm{C}$, gives the expected profit if the competitor has a cost advantage for project $L$ and, hence, bids as if it is a better cost type than $\bar{c}$ and always wins the first auction. Then, firm 1 is the only bidder in the second auction and receives $\bar{c}-$ $m_{1}$. Since these arguments are independent of utilitzed auction designs, the invariance of $E\left[\Pi_{1}^{L+M} \mid\left(l_{1}>m_{1}, m_{1}\right) ; g_{2}().\right]$ completes the proof.

Corollary 9 For any combination of auction designs utilized in class $\Gamma$ for auctions $L$ and $M$, there is revenue equivalence in the sense that each firm receives the same expected payment in each stage auction implying that expected prices and buyers' expected payoffs are constant in each stage auction. 


\section{The Impact of Endogenous Outside Options on Bidding Be- havior}

The standard one-shot procurement auction model abstracts from further procurement contracts offered. For capacity-constrained firms, these alternative transaction opportunities create outside options that affect bidding behavior. In the first auction of our sequential auction game, the second auction endogenizes a firm's outside option. The second auction with competition differs from the standard SIPV model in that both bidders receive a signal about their competitor's cost structure since they observe that their competitor did not bid for the first auction. Here, we analyze how the option value created by the second auction affects bidding behavior in the first auction of our dynamic model. Furthermore, we explore and discuss how bidding behavior in both stages of our dynamic model differs from bidding behavior in the static SIPV model.

The option value that a firm places on the opportunity to participate in the second auction depends on a firm's completion cost for the second project. In particular, if a firm bids in the first auction its opportunity cost of winning is $\bar{c}-m$ since not winning the first auction implies that it remains the only bidder in the second auction. We refer to this opportunity cost as the firm's option value.

To see how a firm revises its bid for the first project in response to changes in its option value, consider a specific example where completion costs are uniformly distributed, $(l, m) \sim$ $U[20,100]^{2}$. (For referees only: The details of derivation and the equilibrium solutions are relegated to the referees' appendix, see p. 27ff.) Figure 3 highlights that equilibrium bidding functions for project $L$ vary with the completion cost for the second project, $m$. It depicts the bidding functions for the values $m=80$ and $m=100$. Obviously, decreases in the option value shift the bidding function downwards. Intuitively, as the firm is faced with larger completion costs for the second project, its option value of winning the second auction declines leading it to place more aggressive bids in the first auction. It follows that option value heterogeneity implies asymmetric equilibrium bidding functions for the first auction. Proposition 10 establishes this result independently of the underlying distribution.

Proposition 10 In the auction for project L, a firm's equilibrium bid increases in its option value created by the subsequent auction.

Proof The option value of participating in the second auction subsequently to not winning the first auction equals $\bar{c}-m$. Since $\bar{c}$ is constant, we obtain $\partial b^{L}(l, m) / \partial(\bar{c}-m)=$ $-\partial b^{L}(l, m) / \partial m$. Differentiating the equilibrium bidding function $b^{L}(\lambda)$ with $\lambda=l+\bar{c}-m$ leads 
to

$$
\frac{\partial b^{L}(l, m)}{\partial m}=\left\{\begin{array}{cl}
-\frac{f_{\lambda}(\lambda) \int_{\lambda}^{\bar{c}}\left[1-F_{\lambda}(x)\right] d x}{[1-F(\lambda)]^{2}}<0 & \text { if } l<m \\
0 & \text { otherwise }
\end{array} .\right.
$$

As a firm's completion cost $m$ decreases, the option value of participating in the second auction, $\bar{c}-m$, increases. Thus, firms with a cost advantage for the first project bid less aggressively for project $L$.

Next we compare bidding behavior in the first auction of the dynamic model with bidding behavior in the static SIPV model using any bivariate uniform distribution of cost pairs with support $[\underline{c}, \bar{c}]^{2}$. In the static SIPV model, the bidding function for the example is $b(l)=50+0.5 l$. This bidding function is depicted in Figure 3, too. As can be readily seen from the Figure, the SIPV bidding function $b(l)$ lies substantially below all bidding functions for the first auction in the sequential model since $b^{L}(l, m=100)$ constitutes their lower bound due to $\partial b^{L} / \partial m<0$. Interestingly, the lower bound of bidding for project $L$ in the sequential model substantially exceeds the SIPV bidding function, although a firm with the most unfavourable completion cost for project $M, m=100$, has option value zero and faces virtually no second auction. The reason why the bidding functions $b^{L}(l, m=100)$ and $b(l)$ do not coincide lies in the fact that the firm's competitor does not know that the firm has unfavourable completion cost for project $M$ and bids less aggressively due to its own option value. It follows that the static SIPV model is no special case of our dynamic auction model with an option value equal to zero. The result that bidding behavior is always more relaxed in the first auction of our dynamic model as compared to bidding behavior in the static SIPV model holds for any bivariate uniform distribution (proposition 11a.)

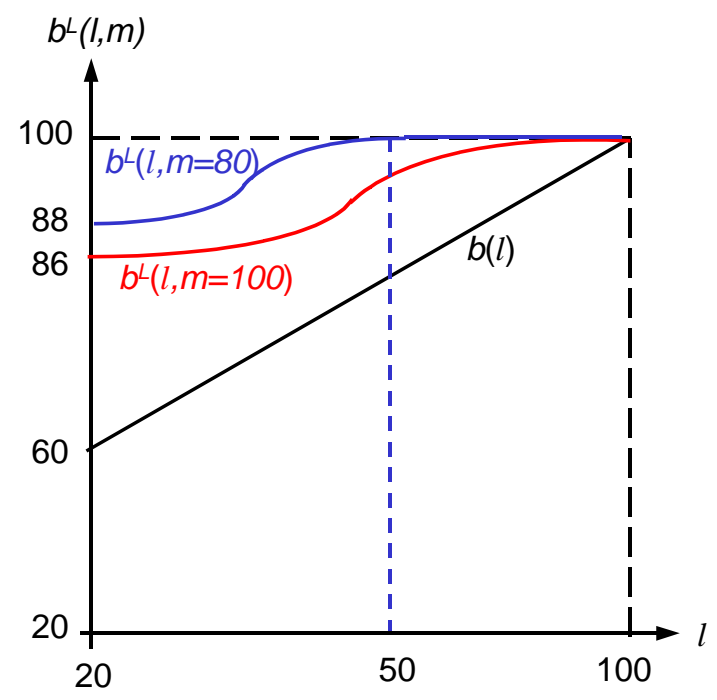

Figure 3: Bidding for project $L$

The comparison of bidding behavior in the static SIPV model with bidding in the second 
auction under competition leads to the reverse result: bidding in the second auction is always more aggressive than in the static SIPV model (proposition 11b) due to endogenous type selection. Since relatively more low-cost types skip the first auction, in the second auction any firm expects its competitor to have a lower cost than in the SIPV model.

Proposition 11 For any bivariate uniform distribution with quadratic support,

(a) equilibrium bidding in the first auction is less aggressive than in the static SIPV model,

(b) equilibrium bidding in the second auction with competition where both bidders are present is more aggressive than in the static SIPV model.

Proof. See the appendix.

The main insight here is that bidding behavior is crucially influenced by the existence of outside options, independently of the auction stage. This carries over to the case of general distributions. However, the particular effects that bidding in the first (second) auction is always less (more) aggressive than in the SIPV model do not necessarily hold. To see this, consider the SIPV model where a firm bids the expected cost of its competitor given that it submits the lower bid (which is equivalent to having the lower cost type.) Suppose now that the competitor is endowed with some option value, transforming the SIPV auction into the first stage of the dynamic model. Again, the firm bids the expected cost of its competitor now including opportunity cost given that it submits the lower bid. Ceteris paribus, the firm's bid increases since all competitor's cost types that have a larger cost in the SIPV model have an even larger cost if the option value is included. However, lower cost types that are ignored by the firm in the SIPV model become larger (opportunity-cost augmented) cost types in the first auction of the dynamic model. Some of these inflated cost types now exceed the firm's cost level potentially biasing downwards expected cost given that the firm submits the lower bid. In the special case, where the firm has the lowest cost type in the SIPV model and wins always, there is no ambiguous effect on bids since there are no lower cost types. Thus, for the lowest cost type bidding is always more aggressive in the SIPV model. However, bidding functions of the SIPV model and the first auction of the dynamic model may intersect for other cost types leading to the counterintuitive result that some firms may bid more aggressively once faced with a sufficiently small outside option. To demonstrate this case consider the following bivariate pdf:

$$
f(l, m)=\left\{\begin{array}{ll}
\frac{\left(e^{2 l-120}+e^{120-2 l}\right)\left(e^{2 m-120}+e^{120-2 m}\right)}{\left(e^{80}-e^{-80}\right)^{2}}, & \text { if }(l, m) \in[20,100]^{2} \\
0 & \text { otherwise }
\end{array} .\right.
$$

In Figure 4, we plot the equilibrium bidding function in the SIPV model and the lower bound of bidding functions in the first auction of the dynamic model for completion cost levels $l \in[20,22]$ for this distribution. Bidding functions for both models intersect at $l=21.06$. 


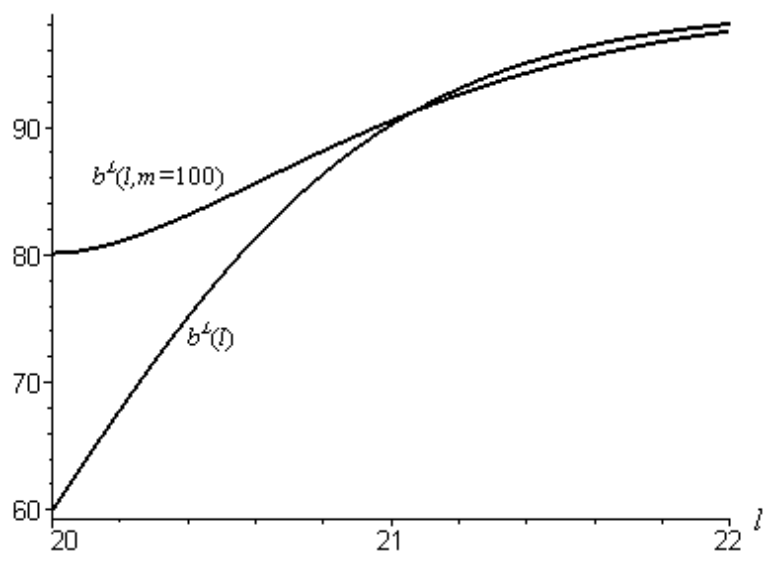

Figure 4: Intersecting equilibrium bidding functions

\section{Conclusion}

Motivated by recent empirical evidence that suggests that (1) firms perceive independent oneshot procurement auctions not in isolation but rather as an auction sequence, that (2) subcontracting isn't perfect and that (3) firms are aware of their opportunity cost, this paper has introduced a sequential procurement auction model to study firms' first-price equilibrium bidding strategies. In contrast to a procurement auction version of Weber (1983) and Elmaghraby (2003), the presented model predicts that firms not always participate in early auctions. In addition bidding behavior in each auction stage strongly depends on the option value that a firm places on remaining auctions contrasting with a procurement auction version of the standard SIPV model. If real-world firms would regard auction stages in a sequence of auction as one-shot games and, thus, would ignore alternative transaction opportunites, the focus on the standard SIPV model is appropriate. The experimental data generated by the implementation of our procurement auction model in the laboratory, see Brosig and Reiss (2007), suggest that the option value of alternative transaction opportunities strongly influences bidding and entry behavior in the lab similiarly to the theoretical predictions and renders our approach relevant. 


\section{Appendix}

\subsection{Proof of lemma 3}

Noting that $m_{1}$ and $b_{1}^{M}$ are constants and substitution for the latter according to proposition 2 leads to

$$
\frac{\int_{m_{1}}^{\bar{c}}\left[1-F_{M_{2} \mid S k i p}(x)\right] d x}{1-F_{M_{2} \mid S k i p}\left(m_{1}\right)} \cdot \int_{m_{1}}^{\bar{c}} \int_{g_{2}\left(m_{2}\right)}^{\bar{c}} f\left(l_{2}, m_{2}\right) d l_{2} d m_{2}=\int_{m_{1}}^{\bar{c}}\left(m_{2}-m_{1}\right) \int_{g_{2}\left(m_{2}\right)}^{\bar{c}} f\left(l_{2}, m_{2}\right) d l_{2} d m_{2}
$$

Since $1-F_{M_{2} \mid \text { Skip }}(x)=\left[\int_{x}^{\bar{c}} \int_{g_{2}(s)}^{\bar{c}} f\left(l_{2}, s\right) d l_{2} d s\right] /\left[\int_{\underline{c}}^{\bar{c}} \int_{g_{2}(t)}^{\bar{c}} f\left(l_{2}, t\right) d l_{2} d t\right]$ we obtain from the last equation

$$
\int_{m_{1}}^{\bar{c}} \int_{x}^{\bar{c}} \int_{g_{2}(s)}^{\bar{c}} f\left(l_{2}, s\right) d l_{2} d s d x=\int_{m_{1}}^{\bar{c}}\left(m_{2}-m_{1}\right) \int_{g_{2}\left(m_{2}\right)}^{\bar{c}} f\left(l_{2}, m_{2}\right) d l_{2} d m_{2}
$$

Let $\phi\left(m_{2}\right)$ be the integral of $\int_{g_{2}\left(m_{2}\right)}^{\bar{c}} f\left(l_{2}, m_{2}\right) d l_{2}$, then integration by parts of the right-hand side using $\iint_{g_{2}\left(m_{2}\right)}^{\bar{c}} f\left(l_{2}, m_{2}\right) d l_{2} d m_{2}=\phi(\bar{c})-\int_{m_{2}}^{\bar{c}} \int_{g_{2}(u)}^{\bar{c}} f\left(l_{2}, u\right) d l_{2} d u$ leads to

$$
\int_{m_{1}}^{\bar{c}} \int_{x}^{\bar{c}} \int_{g_{2}(s)}^{\bar{c}} f\left(l_{2}, s\right) d l_{2} d s d x=\int_{m_{1}}^{\bar{c}} \int_{m_{2}}^{\bar{c}} \int_{g_{2}(s)}^{\bar{c}} f\left(l_{2}, s\right) d l_{2} d s d m_{2}
$$

which obviously holds.

\subsection{Proof of lemma 4}

Suppose $g_{1}\left(m_{1}\right)=\bar{c}$, then firm 1 always enters auction $L$. For $l_{1}=\bar{c}$, the firm never makes any profit from project $L$ such that the strategy to enter auction $L$ and continuing bidding in auction $M$ if possible is profitable only if it doesn't win project $L$ resulting in the same profit as if the firm had skipped auction $L$. If the competitor has a cost advantage for project $M$, it either bids $\bar{c}$ for project $L$ or skips the auction. In both cases, firm 1 wins project $L$ with positive probability although it could have won the profitable auction $M$ in some cases since $m_{1}<\bar{c}$ such that $E\left[\Pi_{1}^{L+M} \mid\left(l_{1}=\bar{c}, m_{1}<\bar{c}\right)\right]<E\left[\Pi_{1}^{M} \mid m_{1}<\bar{c}\right]$. Since $g_{1}\left(m_{1}\right)>\bar{c}$ leads to the same entry strategy as $g_{1}\left(m_{1}\right)=\bar{c}$ implies, it follows that $g_{1}\left(m_{1}\right)<\bar{c}$ for $m_{1} \in[\underline{c}, \bar{c})$.

For $g_{1}\left(m_{1}\right)<\bar{c}$ it follows immediately from (5) that $E\left[\Pi_{1}^{M} \mid m_{1}<\bar{c}\right]<\bar{c}-m_{1}$. If firm 1 has no cost advantage for project $M$, i.e. $l_{1} \leq m_{1}$, according to proposition 2 its bidding behavior guarantees it at least profit $\bar{c}-m_{1}$ for each feasible completion cost pair of its competitor, thus $E\left[\Pi_{1}^{L+M} \mid l_{1} \leq m_{1}<\bar{c}\right] \geq \bar{c}-m_{1}$. Therefore, $g_{1}\left(m_{1}\right)>m_{1}, m_{1} \in[\underline{c}, \bar{c})$.

If $m_{1}=\bar{c}$, then the definition of $g_{1}\left(m_{1}\right)$ directly implies $g_{1}(\bar{c})=\bar{c}$. To see this note that $\left.E\left[\Pi_{1}^{M} \mid m_{1}=\bar{c}\right)\right]=0$ and $E\left[\Pi_{1}^{L+M} \mid(\bar{c}, \bar{c})\right]=0$ while $E\left[\Pi_{1}^{L+M} \mid\left(l_{1}<\bar{c}, \bar{c}\right)\right]>0$ which completes the proof. 


\subsection{Proof of proposition 5}

In order to determine the entry indifference curve $l_{1}^{\text {crit }}=g_{1}\left(m_{1}\right)$ it is sufficient to consider entry condition (1) for firms with a cost advantage for project $M$ since, according to lemma 4, for all other types expected profits strictly exceed opportunity costs. Thus, substitution of the definitions of expected profits from both entry strategies into (4) leads with some minor algebraic manipulations ${ }^{11}$ using the properties of $f(l, m)$ to the implicit definition of the entry indifference curve $l_{1}^{\text {crit }}=g\left(m_{1}\right)$ :

$$
\frac{\bar{c}-m_{1}}{2}+\frac{2 \bar{c}-\left(l_{1}^{c r i t}+m_{1}\right)}{2}\left[\frac{1}{2}-\int_{\underline{c}}^{\bar{c}} \int_{g_{2}\left(m_{2}\right)}^{\bar{c}} f\left(l_{2}, m_{2}\right) d l_{2} d m_{2}\right]+\left(\bar{c}-l_{1}^{c r i t}\right) \int_{\underline{c}}^{\bar{c}} \int_{g_{2}\left(m_{2}\right)}^{\bar{c}} f\left(l_{2}, m_{2}\right) d l_{2} d m_{2}
$$

$$
-\left(\bar{c}-m_{1}\right) \int_{\underline{c}}^{\bar{c}} \int_{\underline{c}}^{g_{2}\left(m_{2}\right)} f\left(l_{2}, m_{2}\right) d l_{2} d m_{2}-\int_{m_{1}}^{\bar{c}} \int_{g_{2}\left(m_{2}\right)}^{\bar{c}}\left(m_{2}-m_{1}\right) \cdot f\left(l_{2}, m_{2}\right) d l_{2} d m_{2}=0 .
$$

Part (b) of the proposition directly implies the existence and the claimed properties of set $G$ in (a). Therefore it is sufficient to show the existence of $g(m)$ satisfying (i)-(iii) to prove the proposition.

The implicit-function theorem implies existence and differentiability of $l_{1}^{\text {crit }}=g_{1}\left(m_{1}\right)$ as defined by (8) for any function $g_{2}\left(m_{2}\right)$. In a symmetric equilibrium, both firms act in accordance with the same equilibrium entry indifference curve denoted by $g(m)$. Thus $g_{1}(m)=g_{2}(m)=g(m)$ and (i) follows from lemma 4. Again, using symmetry of equilibrium entry behavior with identity (8) and subsequent differentiation w.r.t. $m$ leads to

$$
\begin{gathered}
-\frac{g^{\prime}(m)}{2} \int_{\underline{c}}^{\bar{c}} \int_{g\left(m_{2}\right)}^{\bar{c}} f\left(l_{2}, m_{2}\right) d l_{2} d m_{2}-\frac{g^{\prime}(m)}{4}+\frac{1}{4}-\frac{1}{2} \int_{\underline{c}}^{\bar{c}} \int_{g\left(m_{2}\right)}^{\bar{c}} f\left(l_{2}, m_{2}\right) d l_{2} d m_{2} \\
+\int_{m}^{\bar{c}} \int_{g\left(m_{2}\right)}^{\bar{c}} f\left(l_{2}, m_{2}\right) d l_{2} d m_{2}=0 .
\end{gathered}
$$

By (i) $\int_{\underline{c}}^{\bar{c}} \int_{g\left(m_{2}\right)}^{\bar{c}} f\left(l_{2}, m_{2}\right) d l_{2} d m_{2}<\int_{\underline{c}}^{\bar{c}} \int_{m_{2}}^{\bar{c}} f\left(l_{2}, m_{2}\right) d l_{2} d m_{2}$ where the latter equals $1 / 2$, identity (9) implies $g^{\prime}(m)>0$ as claimed in (ii).

Differentiation of $(9)$ w.r.t. $m$ yields

$$
-\frac{g^{\prime \prime}(m)}{2} \int_{\underline{c}}^{\bar{c}} \int_{g\left(m_{2}\right)}^{\bar{c}} f\left(l_{2}, m_{2}\right) d l_{2} d m_{2}-\frac{g^{\prime \prime}(m)}{4}-\int_{g(m)}^{\bar{c}} f\left(l_{2}, m\right) d l_{2}=0
$$

implying (iii).

\footnotetext{
${ }^{11}$ See the referees' appendix.
} 


\subsection{Proof of proposition 11}

(a) We have to show that the difference between the bidding function of our dynamic model for the first auction and the bidding function of the static SIPV model is positive for any bivariate uniform distribution with pdf $f(l, m)=1 /(\bar{c}-\underline{c})^{2} \forall(l, m) \in[\underline{c}, \bar{c}]^{2} \subseteq R_{+}^{2}$. Since there exists a continuum of bidding functions for project $L$ depending on the particular realization of the cost parameter for the second project, $m$, and bids decrease in $m$ (proposition 10), it is sufficient to show that the difference is positive for the largest cost parameter $m=\bar{c}$, i.e.

$$
\Delta(l) \equiv b^{L}(l, m=\bar{c})-b(l)>0, \quad l \in[\underline{c}, \bar{c}),
$$

where equilibrium bidding functions are defined in proposition 2 and lemma 1 . The pdf in the static SIPV model is given by the marginal density function of the bivariate uniform distribution with respect to $L$, i.e. $h(l) \equiv \int_{\underline{c}}^{\bar{c}} f(l, m) d m$. Clearly, $\Delta(l=\bar{c})=0$. Since firms with a cost advantage for the second project, $l \geq m$, submit the largest feasible bid $\bar{c}$ in the auction for project $L$ and bids always fall below $\bar{c}$ in the SIPV model, $b(l<\bar{c})<\bar{c}$, it is sufficient to focus on firms with a cost advantage for the first project, i.e. $l<m$. Then, the difference in equilibrium bids is given by

$$
\Delta(l)=\int_{l}^{\bar{c}}\left[1-F_{\lambda}(x)\right] d x /\left[1-F_{\lambda}(l)\right]-\int_{l}^{\bar{c}}[1-H(x)] d x /[1-H(l)]
$$

recalling that $\lambda \equiv l+\bar{c}-m$. Here, the particular cdfs are $F_{\lambda}(x)=(x-\underline{c})^{2} / 2(\bar{c}-\underline{c})^{2}, x \in[\underline{c}, \bar{c}]$, and $H(x)=(x-\underline{c}) /(\bar{c}-\underline{c}), x \in[\underline{c}, \bar{c}]$. Integrating and rearranging leads to

$$
\begin{aligned}
\Delta(l) & =\frac{1}{6}(\bar{c}-l) \frac{A_{1}}{A_{2}}, \\
A_{1} & =4 \bar{c}^{2}-2 \bar{c} l-6 \bar{c} \underline{c}+l^{2}+3 \underline{c}^{2}, \\
A_{2} & =2 \bar{c}^{2}-4 \bar{c} \underline{c}+\underline{c}^{2}-l^{2}+2 \underline{c} l .
\end{aligned}
$$

Note that $A_{1}$ and $A_{2}$ are always positive and monotone decreasing since $A_{1}(l=\underline{c})=4(\bar{c}-\underline{c})^{2}$, $A_{1}(l=\bar{c})=3(\bar{c}-\underline{c})^{2}$, and $\partial A_{1} / \partial l=2(l-\bar{c}) ; A_{2}(l=\underline{c})=2(\bar{c}-\underline{c})^{2}, A_{2}(l=\bar{c})=(\bar{c}-\underline{c})^{2}$, and $\partial A_{2} / \partial l=2(\underline{c}-l)$. This confirms that $\Delta(l)>0 \forall l \in[\underline{c}, \bar{c})$ proving part (a) of the proposition.

(b) Analogously to part (a), we have to show that the difference between the bidding function of our dynamic model for the second auction and the bidding function of the static SIPV model is negative for any bivariate uniform distribution. Here, the bidding difference is defined by

$\Delta(m) \equiv \int_{m}^{\bar{c}}\left[1-F_{M \mid \text { Skip }}(x)\right] d x /\left[1-F_{M \mid S k i p}(m)\right]-\int_{m}^{\bar{c}}[1-H(x)] d x /[1-H(m)], \quad m \in[\underline{c}, \bar{c})$.

where $F_{M \mid S k i p}(x)$ is defined in proposition 2 and $H(x)$ is given above. Again $\Delta(m=\bar{c})=0$. Using the distributions under the uniformity assumption and rearranging leads to

$$
\Delta(m)=\frac{-\int_{m}^{\bar{c}} \int_{x}^{\bar{c}} g(s) d s d x+\frac{\bar{c}-m}{2} \int_{m}^{\bar{c}} g(s) d s}{\int_{m}^{\bar{c}}[\bar{c}-g(s)] d s} .
$$


Since the denominator is strictly positive for any $m \in[\underline{c}, \bar{c})$, proposition $5 \mathrm{~b}(\mathrm{i})$, it is sufficient to show that the numerator is strictly negative. Using the fact that $(\bar{c}-m) / 2 \int_{m}^{\bar{c}} g(s) d s=$ $1 / 2 \int_{m}^{\bar{c}} \int_{x}^{\bar{c}} g(s) d s d x+1 / 2 \int_{m}^{\bar{c}} \int_{m}^{x} g(s) d s d x, \Delta(m)<0 \forall m \in[\underline{c}, \bar{c})$ if

$$
\int_{m}^{\bar{c}} \int_{x}^{\bar{c}} g(s) d s d x-\int_{m}^{\bar{c}} \int_{m}^{x} g(s) d s d x>0 .
$$

Notice that the integral on the left side is equivalent to $\int_{m}^{\bar{c}} \int_{\bar{c}-x+m}^{\bar{c}} g(s) d s d x$ changing the direction of integration. Rewriting (10) leads to

$$
\int_{m}^{\bar{c}}\left[\int_{m}^{x} g(s+\bar{c}-x)-\int_{m}^{x} g(s) d s\right] d x>0 .
$$

Since the entry indifference curve $g(\cdot)$ is strictly increasing, proposition $5 \mathrm{~b}(\mathrm{ii}), \bar{c}-x>0 \forall x \in$ $(m, \bar{c})$, and the inner integrals cancel at $m$ and $\bar{c}$, the inequality always holds for $m \in[\underline{c}, \bar{c})$. 


\section{Referees' Appendix}

\subsection{Proof of lemma 1}

The given proof is intended to make it comparable to the proof of our proposition (2) and is not exactly that of Cohen and Loeb (1990). However the method we use here is a minor variant of the standard method to derive the symmetric equilibrium function in a first-price sealed bid auction with independent and private valuations for the procurement context. ${ }^{12}$

There are $n$ risk-neutral firms whose project completion costs are private information and distributed independently and identically following pdf $h:[\underline{c}, \bar{c}] \rightarrow R_{+}$where $H(x)$ denotes the corresponding cdf. It is assumed that the symmetric equilibrium bidding function, $b(c)$, is strictly monotonically increasing in $c$. All firms participate in a procurement auction which is first-price sealed-bid such that the lowest bid wins. There is no entry fee and the upper bound for bids is $\bar{c}$,otherwise there is the possibility of an infinite amount the procurer might have to pay for contract completion. Since bids are increasing in project costs, the firm with the lowest cost type wins the project and receives its winning bid as payment.

Suppose all $n-1$ firms bid according to $b(c)$, then firm 1's expected payment is given by

$$
\pi_{1}=\left(b_{1}-c_{1}\right) \cdot\left[1-H\left(b^{-1}\left(b_{1}\right)\right)\right]^{n-1} .
$$

The difference $b_{1}-c_{1}$ is firm 1's surplus if it wins the auction which is multiplied by its winning probability associated with bid $b_{1}$. Particularly, $\left[1-H\left(b^{-1}\left(b_{1}\right)\right)\right]^{n-1}$ is the probability that all other firms have larger costs than $b^{-1}\left(b_{1}\right)$ being the cost type corresponding to the bid of firm 1. If $b_{1}$ is chosen such that (11) is maximized, then total differentiation of $\pi_{1}$ w.r.t. $c_{1}$ leads at the optimum by $\partial \pi_{1}^{*} / \partial b_{1}=0$ to

$$
\frac{d \pi_{1}^{*}}{d c_{1}}=-\left[1-H\left(b^{-1}\left(b_{1}\right)\right)\right]^{n-1}
$$

Integration of this expression in the boundaries $\left[c_{1}, \bar{c}\right]$ yields

$$
\pi_{1}^{*}(\bar{c})-\pi_{1}^{*}\left(c_{1}\right)=-\int_{c_{1}}^{\bar{c}}[1-H(x)]^{n-1} d x
$$

using the fact that in a Nash equilibrium firm 1's profit maximizing bid $b_{1}$ must coincide with the value of the equilibrium bidding function at its true cost type. Noting that a firm with maximum completion costs cannot make any money, $\pi_{1}(\bar{c})=0$, we have

$$
\pi_{1}^{*}\left(c_{1}\right)=\int_{c_{1}}^{\bar{c}}[1-H(x)]^{n-1} d x .
$$

Combining this equation with (11) at the optimum leads to the equilibrium bidding function

$$
b(c)=c+\frac{\int_{c}^{\bar{c}}[1-H(x)]^{n-1} d x}{[1-H(c)]^{n-1}}
$$

\footnotetext{
${ }^{12}$ Cf. Riley and Samuelson (1981), McAfee and McMillan (1987a), or Wolfstetter (1995).
} 
which is equal to the expected second order statistic in the random sample of $n$ cost types conditional on $c$ being the lowest, i.e. the first order statistic.

\subsection{Minor algebraic manipulations: (8)}

Setting expected profits from both entry strategies equal to each other leads to

$$
E\left[\Pi_{1}^{L+M} \mid\left(l_{1}>m_{1}, m_{1}\right)\right]-E\left[\Pi_{1}^{M} \mid m_{1}\right]=0 .
$$

The following terms of the LHS correspond to the terms in the definition of expected profits; the following terms on the RHS are the resulting terms in equation (8); terms which are identical in definitions and (8) are not reproduced.

$$
\begin{aligned}
\int_{\underline{c}}^{\bar{c}} \int_{m_{2}}^{g_{2}\left(m_{2}\right)} \frac{f\left(l_{2}, m_{2}\right)}{2} d l_{2} d m_{2} \cdot\left[2 \bar{c}-\left(l_{1}+m_{1}\right)\right]=\frac{2 \bar{c}-\left(l_{1}^{c r i t}+m_{1}\right)}{2} \int_{\underline{c}}^{\bar{c}} \int_{m_{2}}^{g_{2}\left(m_{2}\right)} f\left(l_{2}, m_{2}\right) d l_{2} d m_{2} \\
=\frac{2 \bar{c}-\left(l_{1}^{c r i t}+m_{1}\right)}{2}\left[\int_{\underline{c}}^{\underline{c}} \int_{m_{2}}^{\bar{c}} f\left(l_{2}, m_{2}\right) d l_{2} d m_{2}-\int_{\underline{c}}^{\bar{c}} \int_{g_{2}\left(m_{2}\right)}^{\bar{c}} f\left(l_{2}, m_{2}\right) d l_{2} d m_{2}\right] \\
=\frac{2 \bar{c}-\left(l_{1}^{c r i t}+m_{1}\right)}{2}\left[\frac{1}{2}-\int_{\underline{c}}^{\bar{c}} \int_{g_{2}\left(m_{2}\right)}^{\bar{c}} f\left(l_{2}, m_{2}\right) d l_{2} d m_{2}\right](\text { since } f(l, m)=f(m, l)) \\
\quad \int_{\underline{c}}^{\bar{c} \int_{\underline{c}}^{m_{2}}} f\left(l_{2}, m_{2}\right) d l_{2} d m_{2} \cdot\left(\bar{c}-m_{1}\right)=\frac{\bar{c}-m_{1}}{2}(\text { since } f(l, m)=f(m, l))
\end{aligned}
$$

\subsection{Proof of Lemma 7, p. 13}

Here we briefly show standard revenue equivalence for a single-shot procurement auction. We use the Envelope-theorem approach. In a procurement context, the firm's expected profit is given by

$$
\Pi\left(b_{i}, c_{i}\right)=R\left(b_{i}, b_{-i}\right)-\operatorname{Pr}\{w i n\} c_{i}
$$

where $R\left(b_{i}, b_{-i}\right)$ is the expected payment of the buyer to the firm if it submits bid $b_{i}$ and its competitors bid according to $b_{-i}$. By definition of the profit function we have

$$
\frac{d \Pi}{d c_{i}}=\frac{\partial \Pi}{\partial b_{i}} \frac{d b_{i}}{d c_{i}}+\frac{\partial \Pi}{\partial c_{i}}
$$

This holds also at the optimum where maximization of $\Pi$ requires $\frac{\partial \Pi}{\partial b_{i}}=0$, thus

$$
\frac{d \Pi}{d c_{i}}=\frac{\partial \Pi}{\partial c_{i}} \text { at the optimum }
$$


We can use the definition of the expected profit function to substitute for the RHS and get:

$$
\frac{d \Pi}{d c_{i}}=-\operatorname{Pr}\{\text { win }\} \text { at the optimum }
$$

Since we conjecture that the equilibrium bidding function is strictly increasing and it must be optimal to bid according to the true type in equilibrium we have

$$
\frac{d \Pi^{*}\left(c_{i}\right)}{d c_{i}}=-\left[1-F\left(c_{i}\right)\right]^{n-1}
$$

where we assume $n$ bidders in the auction. Integrating in the bounds $\left[c_{i}, \bar{c}\right]$ yields

$$
\Pi^{*}\left(c_{i}\right)=\Pi^{*}(\bar{c})+\int_{c_{i}}^{\bar{c}}\left[1-F\left(c_{i}\right)\right]^{n-1} d c_{i}
$$

where the asterisk denotes the maximum expected profit function. Since the highest-cost type always loses the auction in equilibrium and is assumed to have no outside option, $\Pi^{*}(\bar{c})=0$, hence

$$
\Pi^{*}\left(c_{i}\right)=\int_{c_{i}}^{\bar{c}}\left[1-F\left(c_{i}\right)\right]^{n-1} d c_{i}
$$

and with two bidders

$$
\Pi^{*}\left(c_{i}\right)=\int_{c_{i}}^{\bar{c}}\left[1-F\left(c_{i}\right)\right] d c_{i}
$$

In the sequential auction model in auction $M$ given competition, we simply substitute the appropriate cdf into the given expression and obtain the claimed result.

\subsection{A Numerical Example}

In order to illustrate the results of our model, we utilize a bivariate uniform distribution to explicitly determine equilibrium entry and bidding strategies under the first-price sealed-bid auction design with:

$$
f\left(l_{2}, m_{2}\right)=\left\{\begin{array}{cl}
\frac{1}{(\bar{c}-\underline{c})^{2}} & \text { if } \underline{c} \leq l_{2} \leq \bar{c}, \underline{c} \leq m_{2} \leq \bar{c} \\
0 & \text { otherwise }
\end{array} .\right.
$$

Since bidding behavior depends on the entry indifference curve, we begin with the derivation of $g(m)$. Equation (9) implicitly defines $g(m)$ and simplifies with our distributional assumption to the following differential equation:

$$
\begin{aligned}
-\frac{g^{\prime}(m)}{2 \delta} \int_{\underline{c}}^{\bar{c}}\left[\bar{c}-g\left(m_{2}\right)\right] d m_{2}-\frac{g^{\prime}(m)}{4}+ & \frac{1}{4}-\frac{1}{2 \delta} \int_{\underline{c}}^{\bar{c}}\left[\bar{c}-g\left(m_{2}\right)\right] d m_{2} \\
& +\frac{1}{\delta} \int_{m}^{\bar{c}}\left[\bar{c}-g\left(m_{2}\right)\right] d m_{2}=0
\end{aligned}
$$

with $\delta=(\bar{c}-\underline{c})^{2}$. This equation can be reduced to the following second-order differential equation

$$
z^{\prime \prime}(m)-\frac{z(m)}{\delta v_{1}}-\frac{v_{2}}{v_{1}}=0
$$


where

$$
\begin{aligned}
z(m) & =\int_{m}^{\bar{c}}\left[\bar{c}-g\left(m_{2}\right)\right] d m_{2}, \\
v_{1} & =\left[\frac{z(\underline{c})}{2 \delta}+\frac{1}{4}\right], v_{2}=\left[\frac{1}{4}-\frac{z(\underline{c})}{2 \delta}\right] .
\end{aligned}
$$

The general solution of (12) is

$$
z(m)=A_{1} e^{\frac{m}{\sqrt{\delta v_{1}}}}+A_{2} e^{\frac{-m}{\sqrt{\delta v_{1}}}}-\delta v_{2},
$$

where $A_{1}$ and $A_{2}$ are arbitrary constants of integration. The fact that $g(\bar{c})=\bar{c}$ implies $z^{\prime}(\bar{c})=0$ and $z(\bar{c})=0$. In consequence, $A_{1}$ and $A_{2}$ are determined by the following system of equations:

$$
\begin{aligned}
z(\bar{c}) & =A_{1} e^{\frac{\bar{c}}{\sqrt{\delta v_{1}}}}+A_{2} e^{\frac{-\bar{c}}{\sqrt{\delta v_{1}}}}-\delta v_{2}=0 \\
z^{\prime}(\bar{c}) & =\frac{A_{1} e^{\frac{\bar{c}}{\sqrt{\delta v_{1}}}}-A_{2} e^{\frac{-\bar{c}}{\sqrt{\delta v_{1}}}}}{\sqrt{\delta v_{1}}}=0,
\end{aligned}
$$

with solution

$$
A_{1}=\frac{1}{2} \frac{\delta v_{2}}{e^{\left(\bar{c} / \sqrt{\delta v_{1}}\right)}} ; A_{2}=\frac{1}{2} \delta v_{2} e^{\left(\bar{c} / \sqrt{\delta v_{1}}\right)} .
$$

Therefore, the definite solution of (12) is:

$$
z(m)=\frac{1}{2} \delta v_{2}\left[e^{\frac{m-\bar{c}}{\sqrt{\delta v_{1}}}}+e^{\frac{\bar{c}-m}{\sqrt{\delta v_{1}}}}-2\right] .
$$

Note that $v_{1}$ and $v_{2}$ depend on $z(\underline{c})$. For a given parameter $\underline{c}, z(\underline{c})$ can be numerically derived by solving the following equation w.r.t. $z(\underline{c})$.

$$
z(\underline{c})=\frac{1}{2} \delta v_{2}(z(\underline{c}))\left[e^{\frac{m-\bar{c}}{\sqrt{\delta v_{1}(z(\underline{c}))}}}+e^{\frac{\bar{c}-m}{\sqrt{\delta v_{1}(z(\underline{c}))}}}-2\right] .
$$

By construction of (13), $g(m)=\bar{c}+z^{\prime}(m)$ such that the entry indifference curve is given by

$$
g(m)=\bar{c}+\frac{1}{2} \delta v_{2}\left[\frac{e^{\frac{m-\bar{c}}{\sqrt{\delta v_{1}}}}-e^{\frac{\bar{c}-m}{\sqrt{\delta v_{1}}}}}{\sqrt{\delta v_{1}}}\right] .
$$

For the remainder of this example, let the domain of project costs be given by $[\underline{c}, \bar{c}]^{2}=[20,100]^{2}$ implying $\delta=6400, z(20)=1475.4373, v_{1}=0.365$ and $v_{2}=0.135$. For this distribution, the entry indifference curve is given by

$$
g(m)=100+8.938 \cdot\left[e^{\frac{m-100}{48.332}}-e^{\frac{100-m}{48.332}}\right] .
$$

The cdf of opportunity-cost-augmented completion cost levels of project $L$ is given by

$$
F_{\lambda}(x)=\frac{(x-20)^{2}}{12,800} .
$$




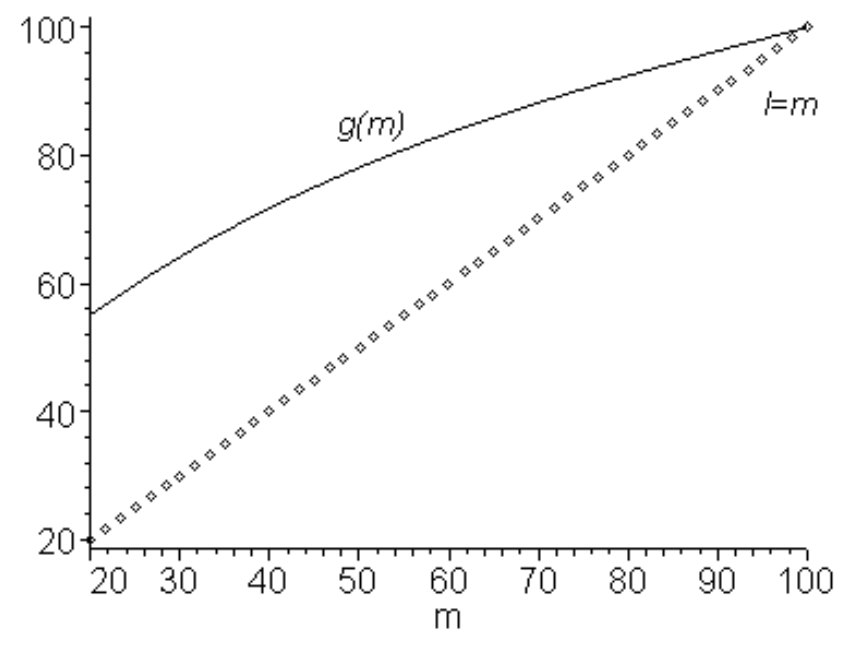

Figure 5: $g(m)$ for $(l, m) \sim U[20,100]^{2}$

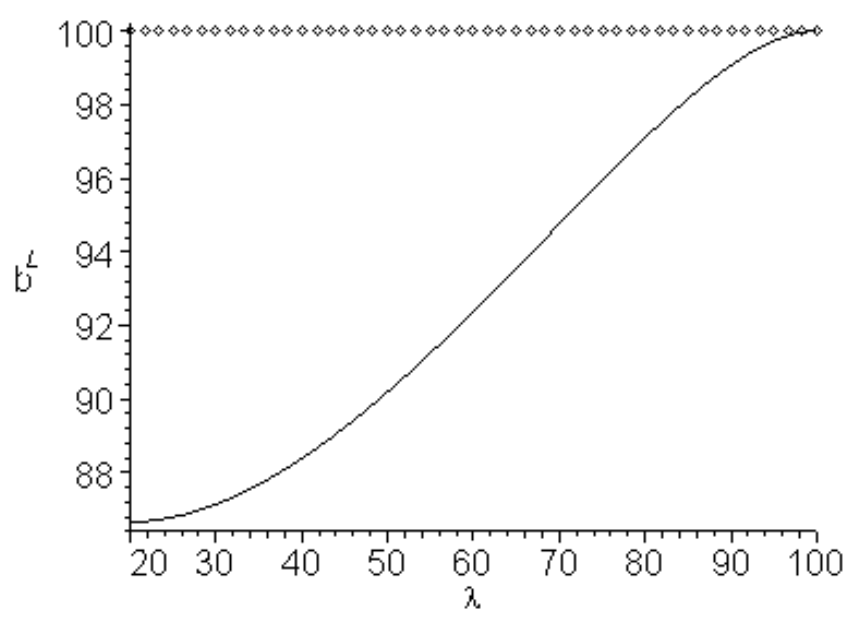

Figure 6: Equilibrium bidding function $b^{L}(\lambda)$

Using this result and the numerical function $g(m)$ with proposition 2a leads to the equilibrium bidding strategy in auction $L$ :

$$
b^{L}(\lambda)=\left\{\begin{array}{cl}
100 & \text { for } g(m) \geq l \geq m \\
\frac{2}{3} \frac{\lambda^{3}-30 \lambda^{2}-1,660,000}{\lambda^{2}-40 \lambda-12,400} & \text { otherwise }
\end{array} .\right.
$$

If both firms don't submit a bid in the first auction, each of them uses this information to update its beliefs about its competitor's distribution of completion costs resulting in the a posteriori density $f_{M \mid \text { Skip }}(x)$ :

$$
f_{M \mid \text { Skip }}(x)=0.00604 \cdot\left[e^{\frac{100-x}{48332}}-e^{\frac{x-100}{48.332}}\right]
$$


According to proposition $2 \mathrm{~b}$, the bidding function of a firm that submits a bid in the second auction $M$ is given by

$$
b^{M}(m)= \begin{cases}100 & \text { if it is the only bidder } \\ m+\frac{0.5839(m-100)+14.110\left[e^{\frac{100-m}{48.332}}-e^{\frac{m-100}{48.332}}\right]}{0.292\left[e^{\frac{100-m}{48.332}}+e^{\frac{m-100}{48.332}}\right]-0.5839} & \text { otherwise }\end{cases}
$$

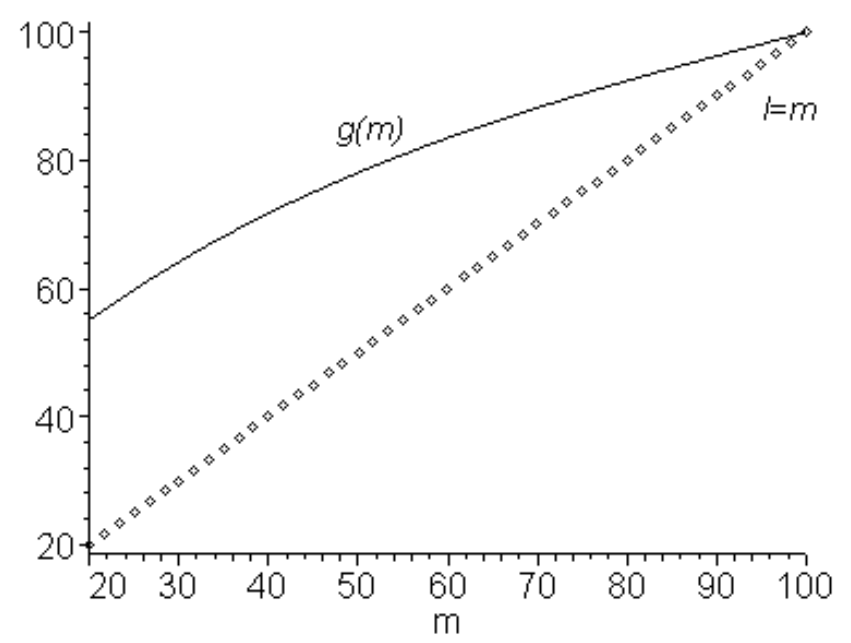

Figure 7: Equilibrium bidding function $b^{M}(m)$ 


\section{References}

[1] Brosig, Jeannette and J. Philipp Reiss (2007), "Entry decisions and bidding behavior in sequential first-price procurement auctions: An experimental study", Games and Economic Behavior 58(1), 50-74.

[2] Cohen, Susan E. and Martin Loeb (1990), "Implicit Cost Allocation and Bidding for Contracts", Management Science 36(9), 1133-1138.

[3] Celentani, Marco and Juan José Ganuza (2002), "Corruption, and competition in procurement", European Economic Review 46(7), 1273-1303.

[4] Dasgupta, Sudipto and Daniel F. Spulber (1989), "Managing Procurement Auctions", Information Economics and Policy 4, 5-29.

[5] De Silva, Dakshina, Timothy Dunne, and Georgia Kosmopoulou (2002), "Sequential bidding in auctions of construction contracts", Economics Letters 76, 239-244.

[6] De Silva, Dakshina, Timothy Dunne, and Georgia Kosmopoulou (2003), "An empirical analysis of entrant and incumbent bidding in road construction auctions", Journal of Industrial Economics 51(3), 295-316.

[7] Elmaghraby, Wedad (2003), "The Importance of Ordering in Sequential Auctions", Management Science 49(5), 673-682.

[8] Gale, Ian L. and Donald B. Hausch (1994), "Bottom-Fishing and Declining Prices in Sequential Auctions", Games and Economic Behavior 7, 318-331.

[9] Gale, Ian L., Hausch, Donald B., and Mark Stegeman (2000), "Sequential Procurement with Subcontracting", International Economic Review 41(4), 989-1020.

[10] Holt, Charles A. (1980), "Competitive Bidding for Contracts under Alternative Auction Procedures", Journal of Political Economy 88(3), 433-445.

[11] Jofre-Bonet, Mireia and Martin Pesendorfer (2000), "Bidding Behavior in a Repeated Procurement Auction", European Economic Review 44 (4-6), 1006-1020.

[12] Jofre-Bonet, Mireia and Martin Pesendorfer (2003), "Estimation of a Dynamic Auction Game", Econometrica 71(5), 1443-1489.

[13] Luton, Richard, and Preston R. McAfee (1986), "Sequential Procurement Auctions", Journal of Public Economics 31(2), 181-195.

[14] Maskin, E. and John Riley (1989), "Optimal Multi-unit Auctions", in: Hahn, F. (ed.), The Economics of Missing Markets, Information and Games, Oxford: Clarendon Press, 312-355. 
[15] McAfee, R. Preston and John McMillan (1987a), "Auctions and Bidding", Journal of Economic Literature 25, 699-738.

[16] McAfee, R. Preston and John McMillan (1987b), A reformulation of the principal-agent model", Rand Journal of Economics 18, 296-307.

[17] Milgrom, Paul R. (1989), "Auctions and Bidding: A Primer", Journal of Economic Perspectives $3(3), 3-22$.

[18] Milgrom, Paul R. and Robert J. Weber (1982), "A Theory of Auctions and Competitive Bidding", Econometrica 50, 1089-1122.

[19] Myerson, Roger B. (1981), "Optimal auction design", Mathematics of Operations Research 6(1), 58-73.

[20] Riley, J. G. and W. F. Samuelson (1981), "Optimal Auctions", American Economic Review 71, 381-392.

[21] Riordan, Michael H. and David Sappington (1987), "Awarding Monopoly Franchises", American Economic Review 77, 375-387.

[22] Vickrey, William (1961), "Counterspeculation, Auctions, and Competitive Sealed Tenders", Journal of Finance 16, 8-37.

[23] Weber, Robert J. (1983), "Multiple Object Auctions" in: R. Engelbrecht-Wiggans, M. Shubik, and R. Stark (eds.), Auctions, Bidding and Contracting: Uses and Theory, New York, NY: New York University Press, 165-191.

[24] Wolfstetter, Elmar (1995), "Auctions: An Introduction", Journal of Economic Surveys 10(4), 367-420. 